\title{
INFRACCIÓN DE UN DERECHO DE MARCA EN PLATAFORMAS DE ECOMMERCE: LA ACTUACIÓN DE LA PLATAFORMA Y EL IMPACTO EN SU RESPONSABILIDAD*
}

\section{INFRINGMENT OF TRADEMARK RIGHT ON ECOMMERCE PLATFORMS: THE PERFORMANCE OF THE PLATFORM AND ITS IMPACT ON ITS LIABILITY}

\author{
ISABEL ANTÓN JUÁREZ \\ Profesora titular acr. de Derecho Internacional privado \\ Universidad Carlos III de Madrid \\ ORCID ID: 0000-0002-5369-2301
}

Recibido: 20.07.2020 / Aceptado: 23.07.2020

DOI: https://doi.org/https://doi.org/10.20318/cdt.2020.5602

\begin{abstract}
Resumen: Las plataformas de comercio electrónico se han convertido en verdaderos protagonistas en el intercambio de bienes y servicios. Muchas de estas plataformas son meros intermediarios y sólo alojan información (servicios de hosting). El papel que realizan otras, especialmente en los últimos años debido a cómo han cambiado los servicios digitales, ha dado lugar a que no sea tan fácil calificar su actividad y mucho menos de englobarla dentro de la consideración de "meros intermediarios" que alojan datos. Sin embargo, determinar el rol, el tipo de actuación de este tipo de prestadores de servicios es un aspecto clave cuando se infringen derechos de propiedad industrial o intelectual en una plataforma de ecommerce. En el presente trabajo vamos a abordar dos análisis. Por un lado, se va a estudiar cuándo una plataforma usa una marca en el sentido del Reglmanto UE 2017/1001, sobre la marca de la Unión Europea. Por el otro, se analizará cuándo una plataforma aunque no use la marca se le puede considerar responsable por las infracciones que sobre la misma se están cometiendo en su plataforma.
\end{abstract}

Palabras clave: marca, plataforma de comercio electrónico, responsabilidad civil.

Abstract: Electronic commerce platforms have become real main characters in the exchange of goods and services. Many of these platforms are mere intermediaries and only host information (hosting services). The role played by others, especially in recent years due to how digital services have changed, has led to the fact that it is not so easy to classify their activity and less include it within the consideration of "mere intermediaries". Nevertheless, this is a key aspect when intellectual or industrial property rights are infringed on an ecommerce platform. In the present paper we are going to approach two analyzes. On the one hand, it is going to study when a platform uses a brand in the sense of EU Regulation 2017/1001, on the European Union trade mark. On the other hand, it will be analyzed when a platform, even if it does not use the brand, can be held responsible for the infractions that are being committed on its platform.

Keywords: trademark, ecommerce platform, civil liability.

*Este trabajo ha sido realizado en el marco del proyecto de investigación: "Los principios del Derecho Romano en el Derecho europeo del siglo XXI - Programa Logos Fundación BBVA de Ayudas a la Investigación en el Área de Estudios Clásicos" 2020-2022. 
Sumario: I. Introducción. II. Las partes involucradas. III. El El uso de la marca ajena en plataformas de ecommerce. A) La oferta de venta de productos que no tienen agotado el derecho de marca. a) Aproximación inicial. b) El asunto Coty Germany vs. Amazon. c) ¿Cuándo se considera que una plataforma de ecommerce usa una marca? B) La oferta de venta on line de productos no procedentes del EEE desde terceros Estados. C)La oferta de venta de artículos de prueba. E) La utilización de marcas como palabras claves en motores de búsqueda. a) El funcionamiento de los motores de búsqueda. b) La jurisprudencia del TJUE. IV. La responsabilidad de las plataformas de comercio electrónico. 1. Aproximación inicial. 2. Los servicios exentos de responsabilidad. 3.El rol de la plataforma en la jurisprudencia del TJUE: ¿ posición neutral o agente activo?. 4. El deber de diligencia de la plataforma. 5. La vía para que la plataforma identifique los hechos ilícitos: la notificación. 6. Medidas que se podrían exigir a la plataforma.V. Conclusiones.

\section{Introducción}

1. El comercio electrónico ha dado lugar a que la distribución comercial se haya transformado por completo. El uso de internet para adquirir bienes y servicios ha crecido exponencialmente en la última década. Además, con la actual pandemia mundial ese incremento se ha multiplicado debido a que las personas que todavía se mostraban reticentes a comprar on line, han acabado haciéndolo ${ }^{1}$. Una gran parte de esas compras on line se realizan a través de plataformas de ecommerce.

2. Sin embargo, del mismo modo que internet presenta aspectos positivos para el consumidor y el desarrollo de los negocios, también se llevan a cabo en la red multitud de infracciones ${ }^{2}$. En particular, en este trabajo vamos a estudiar aquellas que afectan a la propiedad industrial, en especial al derecho de marca y que se cometen desde plataformas de comercio electrónico. Éstas no son ni mucho menos los únicos ilícitos que pueden llegar a existir. Especialmente resultan jurídicamente interesantes aquellos que tienen que ver con la infracción de derechos de autor, la difamación, el fomento de actividades delictivas mediante la red en relación a la responsabilidad que podría albergar las plataformas. Sin embargo, las mismas se escapan del objeto del presente trabajo.

3. Las plataformas de comercio electrónico funcionan como punto de encuentro entre empresarios (B2B), entre empresarios y consumidores (B2C) o entre consumidores (C2C). En principio, su participación en el mercado virtual se limita a ser simples agregadores de oferta y demanda dispersa ${ }^{3}$.

4. Los productos que se venden mediante este tipo de plataformas pueden ser tanto productos falsos o imitaciones como productos de marca que se venden al margen de la red oficial por distribuidores independientes (comercio paralelo) o incluso productos usados ofrecidos por particulares. Es decir, en las plataformas de venta on line se puede encontrar de todo y vendido por cualquiera.

5. Un primer problema que se plantea es que muchas de esas ventas se llevan a cabo sin respetar la imagen de marca y sin ofrecer los servicios que los titulares de las redes oficiales exigen para poder revender los productos. Otro problema es que plataformas de comercio electrónico como eBay, Aliexpress, etc. ofrecen a sus usuarios servicios para crear sus tiendas online, al igual que servicios para promocionarlas para que tengan una mayor acogida entre los consumidores. Junto con los anteriores,

${ }^{1} \mathrm{Vid}$. B. GISPERT, "El comercio electrónico vive una maduración exprés con la pandemia", Diario La Vanguardia, noticia del 25 de mayo de 2020, disponible en www.lavanguardia.com/economia/20200525/481374074471/comercio-electronico-ecommerce-online-alimentacion-moda-r (consultado el 2 de junio de 2020).

${ }^{2}$ Sobre este particular vid. K. WeCKSTRöM, Liability for Trademark infringement for Internet Service Providers, p. 2 disponible en https://papers.ssrn.com/sol3/papers.cfm?abstract id $=1633389$

(consultado el 11 de junio de 2020).

3 Vid. F. CARBAJo CASCÓN, "Problemas de distribución, marcas y responsabilidad indirecta de intermediarios en plataformas de agregación de comercio electrónico. Comentario a la STJUE de 12 de julio de 2012(Caso L'oreal c. eBay) y jurisprudencia relacionada", $R c d, \mathrm{n}^{\circ} 10,2012$, p. 162. 
otro de los servicios publicitarios que ofrecen las plataformas de comercio electrónico a sus usuarios es la aparición en servicios de búsqueda -como Google, Bing, entre otros- mediante la adquisición de palabras claves idénticas o similares a marcas (generalmente renombradas) para hacer aparecer en dicho buscador enlaces patrocinados que lleven al consumidor a la página web del intermediario. De este modo, el consumidor pueda ver la oferta que hace el usuario de dicha plataforma. Esta forma de publicidad se conoce como Keywords Advertising.

También sucede que algunas plataformas de ecommerce como Amazon desempeñan un doble rol. Por un lado, operan como vendedores. Pero por el otro son también intermediarios, permiten que terceros vendan sus productos mediante su plataforma. Sin embargo, en ocasiones esas dos actividades se entremezclan generando incertidumbres a la hora determinar si se está utilizando una marca con esa actuación que desarrolla.

6. Una de las diferentes consecuencias de las diferentes actividades que hemos destacado es que la imagen de la marca puede verse dañada, al igual que los canales de distribución oficiales perjudicados 4 . Por lo tanto, es obvio que el titular de la marca quiera pedir responsabilidades. Así, se puede diferenciar entre la responsabilidad de los usuarios de las plataformas que utilizan la marca ajena sin consentimiento y los titulares de dichas plataformas. La responsabilidad de los primeros podría estar más o menos clara jurídicamente hablando. Sin embargo, la de los responsables de las plataformas es más difícil de dirimir y es uno de los aspectos en los que nos vamos a centrar en el presente trabajo junto con el uso de la marca por parte de una plataforma de ecommerce.

\section{Las partes involucradas}

7. Entre las partes que intervienen en las transacciones que se llevan a cabo mediante plataformas electrónicas es necesario distinguir entre el titular de la plataforma de comercio electrónico (el prestador del servicio) y sus clientes (el destinatario del servicio).

Los clientes son los usuarios de la plataforma que ofrecen productos o los compran a través de aquélla. Esta relación entre los usuarios y la plataforma se regiría por la Ley 34/2002, de 11 de julio, de servicio de la sociedad de la información y del comercio electrónico (en adelante, LSSICE) ${ }^{5}$. Sin embargo, dentro de la misma plataforma surgen otras relaciones comerciales entre los usuarios de ésta que quedan reguladas bajo las reglas del Derecho nacional (Código Civil o Código del Comercio) o de un Derecho extranjero. Esto dependerá de lo que determinen las normas de Derecho internacional privado aplicables a la concreta relación jurídica, ya que estas relaciones pueden ser entre particulares, entre empresarios o entre particulares y empresarios. Junto con la plataforma, sus usuarios y las relaciones que surgen entre éstos también se encontrarían los titulares de marcas y los distribuidores oficiales que se ven afectados por estas transacciones en línea.

8. La actividad de las plataformas de comercio electrónico se diferencia de la de los prestadores de servicio de información puros en que ofrecen no sólo actividades de búsqueda, provisión de enlaces y almacenamiento de datos sino que también llevan a cabo funciones publicitarias (bien ofreciendo enlaces publicitarios u otro tipo de servicio publicitarios), facilitan la difusión de ofertas comerciales y el acceso a información comercial o no comercial proveniente de terceros ${ }^{6}$. Como se estudiará más adelante la responsabilidad de estos operadores va a estar muy relacionada con la función que realizan, si trasciende o no de ser meros intermediarios.

${ }^{4}$ Vid. F. CARBAJo CASCón, "La marca en los sistemas de distribución selectiva (el problema de las ventas paralelas)", en E. GALÁn CoRona/F. CARBAJo CASCón (Coord.), Marcas y distribución comercial, Ediciones Universidad de Salamanca, 2011, p. 205.

${ }^{5}$ BOE núm. 166, de 12 de julio de 2002.

${ }^{6}$ Vid. F. CARBajo CASCón, "Problemas de distribución, marcas y responsabilidad indirecta de intermediarios en plataformas de agregación de comercio electrónico. Comentario a la STJUE de 12 de julio de 2012(Caso L'oreal c. eBay) y jurisprudencia relacionada", $R c d, \mathrm{n}^{\circ} 10,2012$, p. 162. 
9. Por otro lado, el usuario de la plataforma o cliente, el que activamente opera en el mercado electrónico, puede ser una persona física o jurídica. En el caso L'Oreal/eBay se plantea la cuestión de si el titular de la marca puede invocar su derecho únicamente contra los operadores económicos ${ }^{7}$. El TJUE considera que los particulares quedan excluidos de posibles reclamaciones por infracción del derecho de marca debido a que su actividad no queda enmarcada dentro del tráfico económico, salvo que dichas operaciones de particulares, por volumen, frecuencia, u otras razones, superen la mera transacción privada se pueda considerar que el particular está operando como un comerciante ${ }^{8}$.

\section{El uso de la marca ajena en plataformas de ecommerce}

10. En primer lugar, hay que mencionar que no existe regulación sobre la utilización de las marcas en internet. Ni en el Reglamento (UE) 2017/1001 del Parlamento Europeo y del Consejo de 14 de junio de 2017 sobre la marca de la Unión Europea (en adelante, R. 2017/1001) ${ }^{9}$ ni en la Directiva (UE) 2015/2436 del Parlamento Europeo y del Consejo, de 16 de diciembre de 2015, relativa a la aproximación de las legislaciones de los Estados miembros en materia de marcas (en adelante D. 2015/2436) ${ }^{10}$ se recoge nada al respecto. La única mención se recoge en la LM en su art. 34.3 donde se establece que el titular podrá prohibir el uso del signo en redes de comunicación telemáticas y como nombre de dominio.

11. La utilización de la marca ajena en plataformas de comercio electrónico puede realizarse tanto por particulares como por comerciantes, y engloba actividades muy diferentes como las siguientes ${ }^{11}$ :

1) La venta de productos de marca usados;

2) La oferta y/o venta de productos de marca sin embalaje,

3) La productos de marca cuyo derecho no se ha agotado,

4) La productos de marca falsificados,

5) El uso de la marca como palabra clave en motores de búsqueda para productos idénticos o semejantes a los que designa la marca.

12. La cuestión que se plantea es si estas actividades implican uso de la marca y, si es así, si son susceptibles de infringir los derechos del titular de la misma y qué responsabilidad alberga la plataforma de comercio electrónico donde se llevan a cabo estas actividades.

\footnotetext{
7 STJUE 12 julio 2011, L 'Oreal y otros/ eBay Internatial AG y otros, C-324/09, ECLI:EU:C:2011:474, apartados 54.

${ }^{8}$ STJUE 12 julio 2011, L Oreal y otros/ eBay Internatial AG y otros, C-324/09, ECLI:EU:C:2011:474, apartados 54-56. Vid. en sentido contrario F. CARBAJO CASCÓN, "Problemas de distribución, marcas y responsabilidad indirecta de intermediarios en plataformas de agregación de comercio electrónico. Comentario a la STJUE de 12 de julio de 2012(Caso L'oreal c. eBay) y jurisprudencia relacionada", $R c d, \mathrm{n}^{\circ} 10,2012$, pp. 167-168, donde argumenta su desacuerdo a que no se consideren las operaciones aisladas de particulares como operaciones del tráfico económico.

${ }^{9}$ DOUE L 154/1, de 16 de junio de 2017.

${ }^{10}$ DOUE L 336/1, de 23 de diciembre de 2015.

${ }^{11}$ En el año 2018, se detectaron en las distintas aduanas de los Estados miembros 69.000 casos en relación a productos que podían suponer una infracción de Derechos de propiedad industrial o intelenctual. Esos casos afectaban a casi 27.000.000 millones de productos lo que suponía un valor en el comercio al por menor de unos 738.000.000 millones de euros. Los productos que más problemas plantean son el tabaco, los juguetes y la ropa. Para un mayor detalle vid el informe de la Comisión Europea en la materia, Report on the EU Customs enforcement of intellectual property rights, 2019, disponible https://ec.europa.eu/ taxation_customs/sites/taxation/files/2019-ipr-report.pdf, (consultado el 9 de junio de 2020). En la mayoría de estos asuntos el resultado es la destrucción de los productos siguiendo lo que dispone el art. 23 Reglamento UE 608/2013 del Parlamento Europeo y del Consejo de 12 de junio de 2013 relativo a la vigilancia por parte de las autoridades aduaneras del respeto a los derechos de propiedad intellectual y por el que se deroga el Reglamento (CE) No 1383/2003 del Consejo (DOUE L 181/15, de 19 de junio de 2019).
} 


\section{A) La oferta de venta de productos que no tienen agotado el derecho de marca}

\section{a) Aproximación inicial}

13. El supuesto en el que nos encontramos sería el siguiente: el vendedor A comercializa perfumes de la marca $\mathrm{Y}$ a través de una plataforma de comercio electrónico denominada $\mathrm{Z}$. Estos perfumes de la marca $Y$, una marca conocida y cuyo titular en el mercado donde comercializa los productos no es A, es otra empresa conocida como B. La cuestión es que esos productos no tienen agotado el derecho de marca en el $\mathrm{EEE}^{12}$. Es decir, todavía no han sido comercializados en ningún Estado miembro por su titular o por un tercero con el consentimiento de este ${ }^{13}$. Por lo tanto, A no tiene derecho a la venta de esos productos en el EEE, si lo hace, está cometiendo un ilícito marcario.

14. Como se ha señalado, A vende esos productos a través de una plataforma de comercio electrónico. Por lo tanto, cabe preguntarse no tanto por la responsabilidad de A, si efectivamente ese derecho de marca no estuviera agotado estaría cometiendo un ilícito marcario. El derecho de marca no está agotado, y por lo tanto, el comercio paralelo de esos productos no es posible ${ }^{14}$. A nuestro juicio, lo relevante son las actuaciones del titular de la marca con respecto a esa plataforma de comercio electrónico a través de la cual se comercializan los productos. ¿Cuál es el papel de la plataforma?¿De mero intermediario o va más allá? ¿Qué impacto presente ese rol en el uso de la marca? La solución a estos problemas la vamos a realizar teniendo presente la última sentencia del TJUE sobre la materia. Esta es la STJUE de 2 de abril de 2020 donde se enfrentaban Coty (en particular, su filial alemana), gigante estadounidense de la distribución de productos cosméticos y de peluquería y Amazon, la conocida plataforma de comercio electrónico ${ }^{15}$.

\section{b) El asunto Coty Germany vs. Amazon}

\section{i. Los hechos del caso}

15. La citada sentencia del TJUE de 2 de abril de 2020, no aporta demasiada novedad a lo que había establecido el alto tribunal europeo sobre el uso de una marca por una plataforma de ecommerce. Pero esa falta de sorpresa tiene una explicación, y es por cómo se plantea por el Bundesgerichtshof (Tribunal Supremo de lo civil y penal) la cuestión prejudicial. La formulación de esa cuestión prejudicial por el tribu-

\footnotetext{
${ }_{12}$ Sobre el agotamiento del Derecho de marca vid. ad ex. En relación al agotamiento del derecho de marca, Vid. en la doctrina española, A. Bercovitz Rodríguez Cano, Comentario a la ley de marcas, Navarra, Aranzadi, 2008; R. Bercovitz Álvarez, "La utilización de una marca por empresa distinta del titular, como medio de publicitar la reventa o la reparación de productos previamente comercializados por el titular de la misma”, Gaceta Jurídica de la Unión Europea y de la Competencia , n 201, 1999, pp. 59 -67; M. Botana Agra, "El derecho de marca en la jurisprudencia del Tribunal de la CE: de un derecho descafeinado a un derecho con cafeína", Cuadernos de Jurisprudencia sobre propiedad industrial, no 9, 1992, pp. 41 y ss.; A. CASADO CERVIÑO Y C. Borrego, "Agotamiento del derecho de marca", en Comentarios a la Ley y al Reglamento de marcas (C. GonzÁlez BuENo coord.), Madrid, Civitas, 2003, p. 364; T. De las Heras, El agotamiento del derecho de marca, Montecorvo, Madrid, 1994; C. FernándeZ NovoA, Tratado sobre Derecho de marcas, Marcial Pons, MADrID, 2001, PP.371-391; A. GARCía VIDAL, "El alcance territorial del derecho de marca en la reciente jurisprudencia del TJCE”, ADI, 20, 1999; M. Lobato GArCía MiJán, Comentario a la Ley 17/2001, de Marcas, Civitas, 2002, pp. 561 y ss.; P. Martín Aresti, “Art. 36, agotamiento del derecho de marca”, en A. Bercovitz Cano (Dir.)/ J.A García Cruces González (Dir. adjunto), Comentarios a la Ley de Marcas, Tomo I, Aranzadi, 2008; C. Prat, "Comercio paralelo: un flujo de productos y novedades jurídicas que no cesa. La doble perspectiva del derecho marcario y del Derecho antitrust", Gaceta Jurídica de la Unión Europea y de la Competencia, ${ }^{\circ}$ 230, 2004, pp. 27- 44; en la doctrina extranjera vid. per alia A. G. Chronopoulos/ S. M. Maniatis, "Trademark Exhaustation and its Interface with EU Competition Law”, en I. CABoli/E. LeE, Research Handbook on Intellectual Property and Parallel Imports, Edward Elgar Publishing, 2016, disponible en https:// papers.ssrn.com/sol3/papers.cfm?abstract_id=2778247(consultado el 14 de junio de 2020).

${ }^{13}$ De las primeras sentencias en aplicar esta doctrina vid STJUE 16 julio 1998, Silhouette,C-355/96, ECLI:EU:C:1998:374, apartado 18

${ }^{14}$ En relación al comercio paralelo vid. I. ANTÓN JuÁREZ, La distribución y el comercio paralelo en la Unión Europea, La Ley, Madrid, 2015.

${ }^{15}$ STJUE 2 abril 2020, Coty/Amazon, C-567/18, ECLI:EU:C:2020:267.
} 
nal alemán hace en gran medida que la respuesta del TJUE sea bastante previsible, y lo que es peor, no da oportunidad a que se pronuncie sobre la responsabilidad que Amazon podría tener en el supuesto concreto.

16. Los hechos del caso son muy similares a los que se han expuesto anteriormente en el ejemplo anterior donde a la plataforma protagonista la denominábamos Z. Pues bien, esa plataforma Z, ficticia en nuestro ejemplo, aquí es muy real y es Amazon.

17. Un vendedor de Amazon participaba en su programa de "logística", mediante el cual, el vendedor le remite las mercancías a la plataforma de ecommerce y es ésta la se encarga de almacenar los productos, su envío, el servicio de atención al cliente y de las devoluciones. De hecho, como el propio Amazon describe en su web, es la plataforma quien realiza "el trabajo pesado" cuando el cliente de su plataforma contrata este tipo de servicios ${ }^{16}$. Por lo tanto, en 2014 Amazon recibe mediante uno de sus vendedores adscritos al programa "Logística de Amazon" perfumes de la marca Davidoff. El titular de ese signo no era el vendedor de Amazon sino Coty Germany. Ésta argumenta que esos perfumes se están comercializando sin que el Derecho de marca estuviera agotado en el EEE, por lo que se estaba cometiendo una infracción de su derecho de marca. Coty acude ante tribunales alemanes contra Amazon para solicitarle que deje de hacer uso de su marca y que cese en la infracción de la misma.

18. Una de las claves del asunto, es esa acción de cesación sobre el uso de la marca con el fin de evitar que se siga lesionando su derecho. Un aspecto a tener en cuenta es que para que a Amazon se le exija el cese en el uso porque existe infracción, primero se tiene que considerar que está usando la marca en el sentido del R. 2017/1001. Un aspecto a tener presente es que el contrato por el cual se adquiere el producto (en este asunto eran perfumes) es entre el usuario final y el vendedor, no aparece Amazon en esa relación contractual ${ }^{17}$. A efectos de determinar el uso de la marca por Amazon no debería ser determinante. Es un elemento más. Lo importante es averiguar si el papel de Amazon en este caso concreto obedece al de vendedor o al de mero intermediario.

19. Respecto al recorrido judicial del asunto, en las dos primeras instancias, los tribunales alemanes consideran que Amazon con su actuación no hacía uso de la marca de Coty Germany. El Tribunal

\footnotetext{
${ }^{16}$ Así se puede leer en su web https://services.amazon.es/servicios/logistica-de-amazon/funciones-y-ventajas.html (consultado el 8 de junio de 2020). Este hecho también le llama la atención al Abogado General M. CAmpos SÁnchez-BordonA, así lo recoge en sus Conclusiones sobre el asunto presentados el 28 de noviembre de 2019, ECLI:EU:C:2019:1031, apartado 56.

${ }^{17}$ El legislador europeo es consciente de la dificultad que entraña para el consumidor averiguar quién es la otra parte de la relación contractual cuando compra mediante internet. Especialmente cuando la transacción se realiza mediante una plataforma como Amazon pero también otras como Uber. Por ese motivo, han entrado en vigor recientemente dos normas que afectan a los consumidores pero también a las grandes plataformas y a los pequeños empresarios. Estas normas son: 1) la Directiva (UE) 2019/2161 Directiva (UE) 2019/2161 del Parlamento Europeo y del Consejo de 27 de noviembre de 2019 por la que se modifica la Directiva 93/13/CEE del Consejo y las Directivas 98/6/CE, 2005/29/CE y 2011/83/UE del Parlamento Europeo y del Consejo, en lo que atañe a la mejora de la aplicación y la modernización de las normas de protección de los consumidores de la Unión [DOUE L 328/7, de 18 de diciembre de 2019]; 2) El Reglamento (UE) 2019/1150 del Parlamento Europeo y del Consejo, de 20 de junio de 2019, sobre el fomento de la equidad y la transparencia para los usuarios profesionales de servicios de intermediación en línea [DOUE L 186/57, de 11 de julio de 2019]

El fin de esta nueva normativa es conseguir una mayor transparencia, ad ex. la plataforma tendrá la obligación de identificar a la otra parte contratante, precisar si es un comerciante o es un consumidor y sobre todo explicarlo de forma clara para que el consumidor lo comprenda. Hay que tener en cuenta que este particular es especialmente relevante en especial en lo relativo a la economía colaborativa, ya que si el consumidor contrata con otro consumidor no le resultarán de aplicación las garantías adicionales del Real Decreto Legislativo 1/2007, de 16 de noviembre, por el que se aprueba el texto refundido de la Ley General para la Defensa de los Consumidores y Usuarios y otras leyes complementarias (BOE núm. 287, de 30 de noviembre de 2007). La obligación para la plataforma con esta nueva normativa en realidad es de transparencia, que informe al consumidor sobre la identidad de la otra parte contratante y de si son o no de aplicación las normas sobre protección del consumidor. De este modo, la plataforma no tiene la obligación de verificar que quien actúa mediante su plataforma es quien dice ser (considerando 28 Directiva 2019/2161). Esto reduce de forma considerable los costes de la plataforma, no sería responsable si su cliente le miente. En realidad, el deber que recae sobre la plataforma es de transparencia, éste se cumple preguntando a su cliente e informando al consumidor. Para un mayor detalle sobre las implicaciones de esta nueva normativa vid. M. WinNER, "La regulación jurídica de los contratos celebrados a través de plataformas: El Derecho europeo", disponible en https://almacendederecho.org/la-regulacion-juridica-de-los-contratos-celebrados-a-traves-de-plataformas-el-derecho-europeo (consultado el 17 de julio de 2020).
} 
Supremo alemán remite una cuestión prejudicial muy acotada, lo cual como señalábamos anteriormente, condiciona la respuesta del TJUE. Lo que pregunta en esencia es si se puede considerar que una persona "posee" en el sentido del art. 9, apartado 2, letra b y apartado 3, letra b del R. 2017/1001 cuando almacena para un tercero productos que infringen un derecho de marca sin tener conocimiento de dicha infracción, siendo el tercero el que pretende comercializar los productos.

\section{ii. La delimitación de la cuestión prejudicial}

20. A Coty Germany no se le pasa por alto la pregunta tan concreta que remite el Tribunal Supremo alemán al TJUE. La cuestión prejudicial es muy acotada porque al formularla recoge dos presupuestos que limitan directamente la respuesta que puede ofrecer el TJUE. Estos elementos que se incluyen en la cuestión prejudicial y que la condicionan son: 1) la plataforma no tiene conocimiento de que los productos infringen un derecho de marca; 2) la plataforma no tiene intención de ofertar y comercializar los productos, sólo el tercero-vendedor, cliente de Amazon.

Ante este escenario, Coty Germany pone de manifiesto su malestar intentando que la cuestión prejudicial resulte inadmisible. La razón que argumenta es que faltan elementos fácticos claves para entender el problema jurídico ${ }^{18}$. Aunque la cuestión prejudicial es admitida, el TJUE, ante las alegaciones de Coty, solicita a Amazon que precise qué servicios presta mediante su programa de logística.

21. Muy esclarecedor sobre la discrepancia en los hechos y cómo puede afectar a la resolución del Tribunal de Justicia son las Conclusiones del Abogado General CAmpos SÁnchez Bordona. En sus conclusiones diferencia dos escenarios en atención al grado de implicación de Amazon en todo el proceso de oferta y comercialización de los productos ${ }^{19}$. Esto le lleva a contemplar dos soluciones muy diferentes con un grado de responsabilidad para Amazon que varía enormemente y que vamos a analizar más adelante.

\section{c) ¿Cuándo se considera que una plataforma de ecommerce usa una marca?}

22. La diferente jurisprudencia del TJUE, no sólo en el asunto Coty Germany/Amazon, sino también en otros asuntos -Daimler, Mitshubishi, Google Adwords, L'Oreal-, ha precisado que una plataforma de comercio electrónico usa una marca cuando desempeña un papel activo ${ }^{20}$. El TJUE considera que el operador de una plataforma de comercio electrónico que permite que mediante la misma terceros puedan comercializar sus productos no realiza un uso de la marca en atención al art. 9 apartado 2 letra b y apartado 3 letra b del R.2017/1001 cuando almacena los productos, los cuales infringen un derecho de marca pero lo desconoce, siempre que no tenga como fin con ese almacenamiento la oferta o comercialización de los productos ${ }^{21}$.

En otras palabras, cuando ese fin comercial sólo recae en el tercero, el vendedor es el que utiliza la marca para su comercialización y no la plataforma propiamente dicha. De este modo, si la plataforma no usa la marca, tampoco puede infringirla. Además, no se debe pasar por alto que la mera creación de las condiciones técnicas necesarias para que pueda utilizarse una marca y recibir remuneración por ese servicio no significa que el propio prestador de ese servicio esté utilizando el signo ${ }^{22}$.

${ }^{18}$ STJUE 2 abril 2020, Coty/Amazon, C-567/18, ECLI:EU:C:2020:267, apartado 19.

19 Conclusiones del Abogado General Sr. M. Campos Sánchez-Bordona, presentadas el 28 de noviembre de 2019, Coty Germany contra Amazon Services Europe Sàrl y otros, asunto C-567/2018, ECLI:EU:C:2019:1031, apartado 27.

${ }^{20}$ STJUE 2 abril 2020,Coty/Amazon, C-567/18, ECLI:EU:C:2020:267, apartado 37;STJUE de 3 de marzo de 2016, Daimler, C-179/15, ECLI:EU:2016:134, apartados 39 y 40; STJUE de 25 de julio de 2018, Mitshubishi, C-129/17, EU:C:2018:594, apartado 38.

${ }^{21}$ STJUE 2 abril 2020, Coty/Amazon, C-567/18, ECLI:EU:C:2020:267, apartado 45.

${ }^{22}$ STJUE 23 marzo 2010, Google France SARL y Google Inc./Louis Vuitton Malletier, C-236/08 a 238/08,EU:C:2010:159, apartado 57; STJUE 15 de diciembre 2011, Frisdranken Industrie Winters, C-119/10:387, apartado 29; STJUE 2 abril 2020, Coty/Amazon, C-567/18, ECLI:EU:C:2020:267, apartado 43. 
Ante este escenario cabe plantearse si, a pesar de no usar la marca en el sentido mencionado, y por tanto, no infringirla de forma directa, si la plataforma carece de todo tipo de responsabilidad por las infracciones de propiedad industrial que se cometen en su sitio web o aún así puede ser responsable, al menos aunque sea indirectamente, por la infracción de un derecho marcario. Más adelante, abordaremos esta cuestión.

\section{d) La solución del asunto Coty vs. Amazon}

23. La STJUE en el asunto Coty vs Amazon no aporta demasiada novedad, ya que lo que establece el tribunal ya se había señalado en sentencias anteriores. En definitiva, Amazon, en principio, no usaría el signo al almacenar los productos cuando no persigue con ese almacenamiento ofrecer productos o comercializarlos. La razón es que al carecer de tal objetivo no estaría usando la marca en el marco de su propia comunicación comercial ${ }^{23}$.

Sin embargo, es interesante tener en cuenta lo que señala el TJUE en su apartado 48 de la sentencia, y es que deja abierto a que el tribunal nacional pueda entender que la participación de Amazon es mucho más activa de lo que se trasluce de la cuestión prejudicial. Así, el TJUE señala: "Dicho esto, esta conclusión debe entenderse sin perjuicio de la posibilidad de considerar que dichas partes recurridas usan el signo por lo que respecta a los perfumes que posean, no por cuenta de vendedores terceros, sino por cuenta propia o que, en caso de que no puedan identificar al vendedor tercero, sean ofrecidos o comercializados por ellas mismas"

24. A nuestro juicio la realidad es que Amazon no es siempre un mero intermediario y mucho menos cuando sus vendedores utilizan el servicio "Logística de Amazon". En realidad, es Amazon quien realiza todo el trabajo: empaqueta el producto, lo almacena, se lo envía al cliente final y se encarga incluso de las devoluciones y del servicio posventa al cliente.

Por lo tanto, a nuestro parecer, sí usa la marca cuando almacena los productos, por lo menos, cuando sus clientes se suscriben a programas como el de logística, debido a que su participación en la comercialización del producto no es pasiva. Su participación va mucho más allá. Su negocio es doble. Amazon es titular de una plataforma (Amazon marketplace) pero también es vendedor. Así, algunos de los productos que comercializa en su plataforma los pone a la venta el propio Amazon Marketplace pero otros (como es este el caso) provienen de un cliente de Amazon (un vendedor tercero).

La realidad es que al cliente final le cuesta diferenciar cuando un producto lo pone a la venta Amazon o proviene de un tercero ${ }^{24}$. Y más aún cuando sus clientes se suscriben a programas como el de logística, en base a los cuales Amazon es el que se encarga de realizar todo el proceso de venta. Por ese motivo, a nuestro juicio, en un asunto como el que se refleja en la STJUE de 2 de abril de 2020, Amazon sí usaría la marca. Y por lo tanto, sí que debería tener responsabilidad derivada del almacenamiento de mercancías que infringen derechos de propiedad industrial. Lo cual estudiaremos más adelante. No obstante, entendemos la respuesta del TJUE, ya que como señalamos, la pregunta que le realiza el tribunal alemán se circunscribe no sólo a que la plataforma no conocía la infracción marcaria sino que su intención no era comercializar mercancías. Es decir, se parte de que Amazon es un mero intermediario. Aspecto que de entenderse así es clave para determinar su responsabilidad, como estudiaremos posteriormente.

\section{B) La oferta de venta on line de productos no procedentes del EEE desde terceros Estados}

25. Un supuesto relacionado con el anterior se refiere a anuncios y ofertas de venta de productos que no han sido comercializados por el titular de la marca o con su consentimiento dentro del EEE. Lo

\footnotetext{
${ }^{23}$ STJUE 2 abril 2020, Coty/Amazon, C-567/18, ECLI:EU:C:2020:267, apartado 47.

${ }^{24}$ Así lo reconoce el propio Abogado General Sr. M. Campos Sánchez-Bordona, presentadas el 28 de noviembre de 2019, Coty Germany contra Amazon Services Europe Sàrl y otros, asunto C-567/2018, ECLI:EU:C:2019:1031, apartado 54. El legislador europeo es consciente de esta dificultad para el consumidor
} 
diferente aquí es que esa oferta se estaría realizando desde terceros Estados y se dirigiría a consumidores del EEE. El aspecto importante es poder precisar si dichos actos pueden considerarse como una comercialización de los productos de marca en el EEE, y por tanto, están infringiendo el Derecho de marca al no encontrarse dicho derecho agotado ${ }^{25}$.

26. Según el Abogado General JäÄSKINEN en el asunto L`Oreal, es necesario conciliar dos aspectos. Por un lado, el hecho de que los actos se realizan fuera del EEE no significa que se pueda eludir la aplicación de la normativa de la UE cuando dichos actos tienen efectos directos en ella ${ }^{26}$. Pero, por otro lado, no se puede olvidar el carácter global de internet que obliga a matizar dicha doctrina de los efectos si se quieren evitar contradicciones entre normativas de propiedad intelectual.

Así, el Abogado General considera que junto con el efecto objetivo que crea la oferta en la UE hay que valorar si verdaderamente existe intención de vender dichos productos en el $\mathrm{EEE}^{27}$. El Abogado considera que dicha intención debe ser valorada por los tribunales nacionales y recomienda tener como guía para ello el art. 3 de la Recomendación conjunta relativa a las disposiciones sobre la protección de las marcas y otros derechos de propiedad industrial sobre signos de internet de $2001^{28}$.

27. Por su parte, el TJUE en el asunto L 'Oreal consideró contrario al derecho de exclusivo de marca la publicidad y oferta de productos de marca cuando se dirige a consumidores situados en el EEE o cuando la venta se produce de forma efectiva a alguno de sus consumidores ${ }^{29}$. Esto es así debido a que el agotamiento del derecho de marca todavía no se había producido. Al igual que el Abogado General JÄÄSKINEN, el TJUE consideró que son los tribunales nacionales los que deben apreciar en el caso concreto si existen indicios relevantes que muestren que la publicidad $\mathrm{u}$ oferta va dirigida a consumidores de la Unión. En relación a los criterios que pueden utilizarse, el TJUE precisó que podrían ser relevantes las indicaciones que acompañan a la oferta en las que se señalan las zonas geográficas en las que el vendedor está dispuesto a enviar el producto ${ }^{30}$.

\section{C) La oferta de venta de artículos de prueba}

28. Problema íntimamente relacionado con el agotamiento comunitario es la venta de muestras o artículos de prueba que el titular de la marca proporciona a título gratuito a su distribuidor para que los clientes puedan probar el producto antes de adquirirlo. Este tipo de práctica es habitual en cosméticos y perfumes. En los envases de prueba se pueden leer leyendas como "prohibida su venta" o "prueba", para que quede clara la función de este tipo de productos.

29. El TJUE, en el asunto L'Oreal/eBay, siguió lo establecido en pronunciamientos anteriores considerando que no es posible que exista comercialización cuando el titular entrega a sus distribuidores artículos de muestra $^{31}$. De este modo, si los productos designados con dicha marca todavía no se han comercializado en el EEE, el derecho no estará agotado aunque se hayan entregado muestras de los productos al distribuidor. La entrega de muestras no es sinónimo de comercialización de un producto. Así, aunque el derecho exclusivo de marca esté agotado en el EEE el titular puede oponerse a la venta de productos de

${ }^{25} \mathrm{Vid}$. F. Carbajo Cascón, "Problemas de distribución, marcas y responsabilidad indirecta de intermediarios en plataformas de agregación de comercio electrónico. Comentario a la STJUE 12 julio 2012(Caso L'oreal c. eBay) y jurisprudencia relacionada", $R c d, \mathrm{n}^{\circ} 10,2012$, pp. 168-169.

${ }^{26}$ Conclusiones del Abogado General Jääskinen presentadas el 9 de diciembre de 2010, L'Oreal/eBay y otros, asunto C-324/09, ECLI:EU:C:2012:42, apartado 125.

27 Ibidem, apartado 127.

${ }^{28}$ Publicación OMPI 845, disponible en http://www.wipo.int/about-ip/es/development_iplaw/pub845.htm (consultado el 13 de junio 2020).

${ }^{29}$ STJUE 12 julio 2011, L Oreal y otros/ eBay Internatial AG y otros, C-324/09, ECLI:EU:C:2011:474, apartado 67.

${ }^{30}$ Ibidem, apartado 65.

${ }^{31}$ STJUE 3 junio 2010, Coty Prestige Lancaster Group, C-127/09, Rec. 2010, p. I-04965, apartados 42-48; STJCE 15 enero 2009, Silberquelle/Maselli-Strickmode, C-495/07, Rec. 2009, p. I-00137, apartados 20-22. 
prueba debido a que su venta está prohibida. Por lo tanto, que la oferta de productos de muestra se lleve a cabo on line u off line es indiferente para que el titular pueda oponerse a la misma por infracción de su derecho de marca.

\section{D) La venta de productos sin embalaje}

30. En el asunto $L$ 'Oreal/eBay se plantea la venta de productos sin embalaje mediante dicha plataforma. El TJUE consideró necesario, en atención a la diversidad de perfumes y cosméticos, determinar caso por caso cuándo la venta sin embalaje puede ser contraria al Derecho comunitario de marcas ${ }^{32}$. El titular de la marca va a poder oponerse a la venta on line de productos sin embalaje en base a dos infracciones diferentes de su derecho exclusivo de marca (arts. 5 DM y 9 RMC).

Por un lado, por vulnerar la función de indicar el origen del producto. Por el otro, por lesionar la reputación de la marca.

En cuanto a la primera infracción, hay determinados productos en los que las indicaciones sobre los datos del fabricante, el lote de fabricación al que pertenece o los ingredientes del producto se mencionan en el embalaje. De este modo, si el producto se vende sin el embalaje puede provocar que el consumidor no sepa la procedencia empresarial del mismo ${ }^{33}$.

En cuanto al segundo, la imagen de prestigio de la marca también puede verse perjudicada en la venta sin embalaje cuando éste contribuye del mismo modo o más que el producto a proporcionar esa imagen de glamour que caracteriza a la marca. Sin embargo, esto no siempre tiene que ser así, la venta sin embalaje puede no perjudicar en nada a la imagen de la marca en los casos en los que el embalaje no aporte nada especial a aquella ${ }^{34}$. El perjuicio a la imagen de la marca deberá ser demostrado por el titular en el caso concreto porque va a depender mucho del producto en cuestión.

\section{E) La utilización de marcas como palabras claves en motores de búsqueda}

\section{a) El funcionamiento de los motores de búsqueda}

31. El uso de la marca en internet que vamos a abordar es diferente a los usos de la marca estudiados hasta ahora. El problema a afrontar consiste en determinar si se usa la marca, y a su vez, si existe infracción de la misma, cuando una plataforma de comercio electrónico adquiere en motores de búsqueda palabras claves idénticas o similares a marcas ajenas con el fin de hacer publicidad de su sitio web y de los productos ofrecidos en su plataforma por terceros. Sin embargo, aunque nos centremos en los enlaces patrocinados, no son el único uso de este tipo que el titular de la marca podría perseguir. Así, se pueden destacar los siguientes: la aparición de la marca en una página web ajena, el linking o hiperenlace y el framing o enmarcado, el nombre de dominio y las metatags o metaetiquetas ${ }^{35}$.

32. Los motores de búsqueda, como Google, Bing o Yahoo!, ofrecen dos tipos de resultados. Un resultado son los enlaces "naturales u orgánicos" que son el resultado de lo que el buscador considera

${ }^{32}$ STJUE 12 julio 2011, L Oreal y otros/ eBay Internatial A G y otros, asunto C-324/09, ECLI:EU:C:2011:474, apartado 78.

${ }^{33}$ Ibidem, apartado 80.

${ }^{34}$ Conclusiones del Abogado General Jääskinen presentadas el 9 de diciembre de 2010, L'Oreal/eBay y otros, asunto C-324/09, Rec. 2011, p. 0000, apartados 71-73.

${ }^{35}$ Para un mayor detalle sobre otros tipos de usos de las marcas en internet vid. A. GARCía VIDAL, Derecho de marcas $e$ Internet, Tirant Lo Blanch, Valencia, 2002, pp. 57-286; P. DE Miguel Asensio, "Derechos de propiedad industrial", en P. DE Miguel Asensio, Derecho privado de internet, $5^{\text {a }}$ ed., Civitas-Thomson Reuters, 2015;L. SÁnchez Pérez, "La infracción del derecho de marca a través del uso del Keyword advertising: aproximación al reciente posicionamiento jurisprudencial comunitario", $R c d$, no 11, 2012, p. 149; B. Torrubia Chalmeta, La infracción del derecho de marca en Internet, Revista de Internet, Derecho y Politica, $\mathrm{n}^{\circ}$ 9, 2009. Disponible en http://idp.uoc.edu/ojs/index.php/idp/article/view/n9_torrubia/n9_torrubia_esp (consultado el 7 de junio de 2020). 
más relevante en base a diferentes patrones y algoritmos. Mientras que el otro son los resultados denominados "patrocinados o inorgánicos". Estos últimos son por los que el anunciante paga para que, al introducir una o varias palabras claves seleccionadas previamente como términos de referencia, el anuncio del sitio web aparezca en primera posición o dentro de las primeras ${ }^{36}$. Estos resultados son anuncios en realidad, así lo reconoce Google actualmente, son fácilmente identificables debido a que se diferencian del resto por su color de fondo y se sitúan en la parte superior o en la lateral derecha de la pantalla.

33. Los keywords o palabras clave que los buscadores venden al mejor postor pueden ser desde nombres propios hasta nombres comunes o marcas. El uso de las marcas como palabras claves es donde se están planteando más problemas. No sólo porque se trata de una materia en desarrollo, sino también por la complejidad jurídica de estos litigios que exigen un gran dominio multidisciplinar.

\section{b) La jurisprudencia del TJUE}

34. El TJUE, en las sentencias existentes sobre las palabras claves y enlaces patrocinados en Google, diferencia entre la actividad del anunciante y la del prestador del servicio.

35. En la sentencia Google France/Louis Vuitton, al igual que en el resto que la han sucedido respecto al uso de marcas como palabras clave, el TJUE consideró que no hay duda de que el anunciante, el que paga por el enlace patrocinado, sí usa la marca en el tráfico económico, ya que con la palabra clave redirige a los usuarios a un enlace promocional que les lleva a la web donde oferta sus productos y/o servicios ${ }^{37}$. Además, el citado Tribunal consideró que el uso de la marca ajena como palabra clave que conduce al enlace patrocinado del anunciante es un uso en relación a productos o servicios, aunque no se realice en el mismo sitio web del anunciante y a pesar de que dicho uso no venga recogido en el elenco de prohibiciones que tienen a su disposición los titulares de las marcas en los arts. 5 de la Primera Directiva de marcas (actual) y 9.2 RMUE $^{38}$.

36. En relación a los prestadores de servicio, el motor de búsqueda que almacena como palabras claves signos idénticos a marcas, o la plataforma de comercio electrónico que utiliza palabras claves que se corresponde con marcas para publicitar su propio servicio actúan con ánimo de lucro y ejercen una actividad comercial ${ }^{39}$.

En el supuesto de los motores de búsqueda, el TJUE estimó en el caso Google que en la prestación de dichos servicios no se está usando la marca en el sentido y el art. 9 R.2017/1001. El TJUE entiende que ni si quiera en los casos en los que el motor de búsqueda almacena palabras clave asociadas a términos como "imitación" o "copia" y permite que aparezcan anuncios de comerciantes que venden esos productos estaría usando la marca ${ }^{40}$. Esto es así debido a que cuando Google hace depender la aparición de un anuncio de que el usuario introduzca una palabra clave, el buscador no está distinguiendo sus servicios con dicha marca y, por tanto, dicho uso no es un uso de la marca propiamente dicho ${ }^{41}$. De

36 Vid. L. SÁnchez Pérez, "La infracción del...", p. 151.

${ }^{37}$ STJUE 23 marzo 2010, Google France SARL y Google Inc./Louis Vuitton Malletier, C-236/08 a 238/08, EU:C:2010:159, apartado 52; STJUE 25 de marzo 2010, BergSpechte, C-278/08, Rec. 2010, p I-02517, apartado 18; STJUE 22 de septiembre 2011, Interflora/Marks \& Spencer, C-323/09,

ECLI:EU:C:2011:604,apartado 30. Vid. un análisis de estas resoluciones en C. Morcom, "Trade marks and the Internet: where are now?", IPLR, 34(1), 2012, pp. 40-53.

$38 \mathrm{Vid}$. L. A. Marco Alcalá, "Las infracciones del derecho de marca mediante palabras clave en los motores de búsqueda de internet en la jurisprudencia del Tribunal de Justicia de la Unión Europea [Comentario a las SS acumuladas TJUE (Gran Sala) C-236/2008 a C-238/2008, Google France SARL y Google Inc. c. Louis Vuitton Malletier, S.A., Viaticum S.A., Luteciel SARL y otros, de 23 de marzo de 2010 -caso Google-]", ADI 30 (2009-2010), pp. 678-679.

${ }_{39}$ STJUE 23 marzo 2010, Google France SARL y Google Inc./Louis Vuitton Malletier, C-236/08 a 238/08,EU:C:2010:159, apartados 53-59.

${ }^{40}$ STJUE 23 marzo 2010, Google France SARL y Google Inc./Louis Vuitton Malletier, C-236/08 a 238/08,EU:C:2010:159, apartado 104

${ }^{41}$ Vid. L. SÁnchez Pérez, "La infracción del..., p 161. 
este modo, como ya se ha analizado en el asunto Coty Germany/Amazon, al no existir uso de la marca en el tráfico económico tampoco puede haber infracción.

Sin embargo, en el caso de las plataformas de comercio electrónico como eBay, el TJUE entendió que tienen la condición de anunciantes cuando realizan publicidad de su sitio web y de las ofertas de sus clientes en el mismo ${ }^{42}$. Por lo tanto, para saber si el titular puede oponerse a los actos de dichas plataformas conforme al derecho de marcas es necesario precisar si dichos anuncios los realizan en relación a productos semejantes o idénticos que los de la marca registrada ajena y si dichos anuncios afectan negativamente a alguna de las funciones de la marca ${ }^{43}$.

37. Respeto a la primera cuestión, el uso de la marca L'Oreal por eBay se hacía con el fin de promocionar su plataforma de comercio electrónico mediante enlaces patrocinados. Por lo tanto, es obvio que eBay no utiliza la marca para designar productos o servicios idénticos o similares para los que la marca está registrada. Sin embargo, es necesario tener en cuenta que en el caso de marcas renombradas $-L$ 'Oreal y sus marcas lo son- el principio de especialidad que opera en el derecho de marcas se pierde, y por tanto el titular de la marca podría prohibir el uso de su marca para productos o servicios diferentes para los que está registrada la marca (art. 5.2 Primera Directiva de Marcas y 9.1 .c) RMC).

38. Respecto al uso de la marca ajena para productos idénticos por parte de eBay, el TJUE destaca que eBay, al usar marcas de L'Oreal para promocionar ofertas de productos que proceden de sus clientes vendedores, ha hecho uso de la marca en relación a productos o servicios idénticos ${ }^{44}$. El Tribunal destaca que "la expresión "para productos o servicios» no se refiere exclusivamente a los productos o los servicios del tercero que hace uso de los signos que se corresponden con marcas, sino que también puede tener por objeto productos o servicios de otras personas". Así, el hecho de que un operador como eBay haya utilizado un signo que se corresponde con una marca, para productos que no son sus propios productos sino que son de su cliente que los oferta en su plataforma, no impide que se le aplique el art. 5 de la Primera Directiva de marcas cuando se realiza de forma que se establece un vínculo entre tal signo y el servicio que presta el tercero, en este caso $e B a y^{45}$.

39. En sentido contrario, como ha vuelto a sostener el TJUE en el asunto Coty Germany/Amazon, considera que no existe tal uso de la marca en sentido del art. 5 de la Primera Directiva por parte de la plataforma de e-commerce cuando sus clientes-vendedores realizan ofertas de productos de marca en la misma plataforma ${ }^{46}$. En esos casos, es el cliente-vendedor el que hace uso de la marca para su propia comunicación comercial pero no la plataforma, que en principio su única actuación es la de permitir el alojamiento de datos.

40. Una vez estudiado que las plataformas de comercio electrónico hacen uso de la marca cuando adquieren palabras claves en motores de búsqueda para hacer publicidad de su sitio, es necesario determinar si dicho uso vulnera alguna de las funciones de la marca -indicación del origen, imagen, inversión y publicidad-

En relación a la indicación del origen, el TJUE, en el asunto L'Oreal/eBay, siguiendo la doctrina sentada en anteriores resoluciones, considera que el operador de la plataforma eBay vulnera la función de indicación de origen de la marca cuando no permite o apenas permite al internauta medianamente informado y razonablemente atento determinar si tales productos proceden del titular de la marca o de una

${ }^{42}$ STJUE 12 de julio 2011, L Oreal y otros/ eBay Internatial A G y otros, C-324/09, ECLI:EU:C:2011:474, apartado 85.

43 Vid. F. CARBAJo CASCón, "Problemas de distribución, marcas y responsabilidad indirecta de intermediarios en plataformas de agregación de comercio electrónico. Comentario a la STJUE de 12 de julio de 2012(Caso L'oreal c. eBay) y jurisprudencia relacionada", $R c d, \mathrm{n}^{\circ} 10,2012$, p. 172.

${ }^{44}$ STJUE 12 julio 2011, L Oreal y otros/ eBay Internatial AG y otros, C-324/09, ECLI:EU:C:2011:474, apartado 90.

${ }^{45}$ Ibidem, apartados 91 y 92.

${ }^{46}$ STJUE 12 de julio 2011, L Oreal y otros/ eBay Internatial A G y otros, C-324/09, ECLI:EU:C:2011:474, apartados 100-105. 
empresa económicamente vinculada a ésta, o de un tercero ${ }^{47}$. Esta apreciación del Tribunal de Justicia es bastante amplia por lo que deja a los tribunales de los Estados miembros un importante margen de actuación en atención a las circunstancias concretas del caso $^{48}$. De este modo, habrá palabras que sí puedan menoscabar el origen y otras que no. No habrá confusión cuando las palabras obedezcan a términos muy generales, pero sí que lo puede haber cuando las palabras de búsqueda no sean un término general y sean usadas para un producto o servicio idéntico o semejante al del titular de la marca.

Respecto a la función publicitaria, el TJUE considera que dicha función no se lesiona en atención al principio de agotamiento comunitario cuando se use un signo idéntico o similar al de la marca registrada de un tercero para dar publicidad a ofertas en internet de reventa de productos originales designados con dicha marca ${ }^{49}$. Es decir, el revendedor va a poder usar la marca como palabra clave en un motor de búsqueda para revender los productos de dicha marca cuando el derecho exclusivo ya está agotado conforme el art. 7.1 Primera Directiva de marcas, incluso aunque dichos productos que se revendan sean de segunda mano ${ }^{50}$. Todo lo anterior, siempre y cuando los productos no se vendan en unas condiciones que permitan al titular de la marca plantear la excepción al agotamiento conforme al art 7.2 de la citada Directiva o que la publicidad se realice de tal forma que el consumidor pueda llegar a pensar que existe un vínculo entre el titular de la marca y el anunciante.

41. La regla general es que el uso de la marca como palabra clave asociada a un enlace patrocinado no menoscaba la función publicitaria de la marca, puesto que la marca no tiene como función proteger a su titular de las prácticas derivadas del juego de la competencia, entre las que se encuentra la publicidad en internet mediante palabras claves. El objetivo de estas prácticas no es otro que ofrecer al consumidor productos alternativos a los del titular de la marca ${ }^{51}$.

42. Por lo tanto, respecto a los anuncios publicitarios llevados a cabo por las plataformas de comercio electrónico mediante la adquisición de palabras claves en motores de búsqueda es necesario diferenciar, para apreciar la infracción del derecho de marca, los casos en los que el agregador comercial se limita únicamente a anunciar su web, de los casos en los que el anuncio se refiere a ofertas en páginas interiores del sitio en línea de sus clientes ${ }^{52}$. En el primer caso, los anuncios pueden considerarse incluidos dentro de una competencia sana en la que la plataforma lo que busca es anunciar sus servicios. Sin embargo, cuando las plataformas anuncian las ofertas de sus clientes mediante palabras claves que coinciden con marcas de terceros para productos que pueden ir desde falsificaciones hasta productos usados, la infracción de la función publicitaria de la marca podría tener lugar ${ }^{53}$.

${ }^{47}$ STJUE 12 julio 2011, L 'Oreal y otros/ eBay Internatial AG y otros, C-324/09, Rec. 2011, p. 0000, apartado 97; STJUE 23 marzo 2010, Google France SARL y Google Inc./Louis Vuitton Malletier, C-236/08 a 238/08,EU:C:2010:159, apartados 8690. STJUE de 12 de julio de 2011, L Oreal y otros/ eBay Internatial AG y otros, C-324/09, ECLI:EU:C:2011:474, apartado 90.

${ }^{48}$ En la jurisprudencia española vid. un asunto donde se consideraba que no se lesionaba la marca STS de 15 de febrero de 2017, n' 94/2017, FJ 5, "El anuncio de Citylift al que remite el enlace patrocinado en el que la palabra «orona» es utilizada como palabra clave o keyword propone una alternativa a los servicios del titular de la marca notoria, sin ofrecer una imitación de tales servicios, sin causar una dilución de la marca y sin menoscabar sus demás funciones, por lo que supone una competencia sana y leal en el sector de los servicios de mantenimiento de ascensores que, por tanto, constituye la «justa causa» que excluye la antijuridicidad de la conducta. Por tal razón, si consiguen superar el control propio de la Ley de Marcas, no es posible que esos mismos hechos constituyan competencia desleal por las mismas razones relevantes para realizar el enjuiciamiento de la licitud de su conducta con base en la normativa marcaria". Otro donde si se considera que se lesiona la marca, vid. Sentencia Juzgado $\mathrm{n}^{\mathrm{o}} 2$ de lo mercantil de 10 de febrero de 2014, $\mathrm{n}^{\circ}$ 36/2014, ECLI:ES:JMA:2014:16, FJ 2, en la que se condena por infracción del derecho de marca a la empresa demandada por el uso como palabra clave en Google de términos que son idénticos a una marca registrada por el demandante. Se considera que infringe los arts. 34 LM y 9 Reglamento Marca comunitaria debido a que se usan los signos distintivos con fines comerciales y publicitarios en medios telemáticos.

${ }^{49}$ STJUE 8 julio 2010, Portakabin Ltd y Portakabin BV/Primakabin BV, asunto C-558/08, ECLI:EU:C:2010:416, apartado 92.

${ }^{50}$ Ibidem, apartado 91.

${ }^{51}$ STJUE 22 septiembre 2011, Interflora/Marks \& Spencer, asunto C-323/09, ECLI:EU:C:2011:604, apartados 54-59.

52 Vid. F. Carbajo Cascón, "Problemas de distribución..., p. 175.

${ }^{53}$ STJUE 22 de septiembre 2011, Interflora/Marks \& Spencer, C-323/09, ECLI:EU:C:2011:604; STJUE 8 julio 2010 , Portakabin Ltd y Portakabin BV/Primakabin BV, C-558/08, ECLI:EU:C:2010:416. 
43. En relación a la función de inversión, ésta consiste en la posibilidad que tiene el titular de la marca de adquirir o conservar una reputación que le permita atraer a los consumidores y ganarse una clientela fie ${ }^{54}$. Que una marca ostente buena reputación es cuestión de un gran esfuerzo realizado durante años. Este esfuerzo que se premia mediante la buena reputación de una marca en el mercado no sólo se consigue mediante la publicidad sino también mediante otras prácticas comerciales que muestran al cliente el esfuerzo continuado de la marca por ofrecer un buen producto o servicio, ad ex. ofreciendo un servicio posventa de calidad. El uso por un tercero de un signo idéntico a una marca ajena para productos o servicios idénticos para los que está registrada implica un obstáculo para que el titular puede conseguir o mantener la reputación de la marca. Esto es así debido a que el tercero que usa la marca sin consentimiento no busca cuidar la reputación de la marca, sino simplemente vender productos. En nuestra opinión, el menoscabo de la función de inversión de la marca por la plataforma de comercio electrónico al adquirir Keywords en buscadores puede tener lugar cuando se usa la marca para productos falsificados. Especialmente esta infracción podría cobrar más sentido cuando la plataforma tenga como política la prohibición de venta de imitaciones. En el supuesto de productos originales, el problema tendría diferente solución. La infracción o no de la función de inversión, depende de cómo se vaya a llevar a cabo la reventa del producto, con o sin embalaje, si éste presenta algún defecto, pero en ese caso, habría que estudiar el rol que desempeña la plataforma en esa comercialización, ya que si su papel es de mero intermediario, no se trataría de una infracción del derecho de marca llevada a cabo por la plataforma sino del propio revendedor y cliente de la misma. Aquí es clave saber cuáles son las funciones de la plataforma, mero alojador de datos o también vendedor, si su papel en la comercialización de los productos es importante (almacena, empaqueta, envía...) puede menoscabar la función de inversión. Sin embargo, si su papel es de puro intermediario, cómo revende un cliente de su plataforma sus productos no será un aspecto que se le pueda exigir a la plataforma.

44. Por último, en cuanto a la imagen de la marca o goodwill, ésta puede ser lesionada mediante estas prácticas publicitarias vía internet en los casos en los que dicha imagen se debilite. En el caso $L^{\prime}$ Oreal, el TJUE deja abierta la posibilidad de que el juez nacional lo analice en el caso concreto ${ }^{55}$.

\section{La responsabilidad de las plataformas de comercio electrónico}

\section{Aproximación inicial}

45. El segundo problema jurídico a analizar es el relativo a la responsabilidad de la plataforma. Una plataforma puede no usar la marca en el sentido del R. 2017/1001, sin embargo, eso no significa que de esas violaciones de la propiedad industrial que se cometen desde su plataforma por terceros no se le puede pedir responsabilidad civil. Como se estudiará, todo dependerá de la actuación de la plataforma. La norma a analizar para determinar la responsabilidad de las plataformas de ecommerce es la Directiva 2000/31/CE del Parlamento Europeo y del Consejo, de 8 de junio de 2000, relativa a determinados aspectos jurídicos de los servicios de la sociedad de la información, en particular el comercio electrónico en el mercado interior (Directiva sobre el comercio electrónico)[en adelante, DCE] ${ }^{56}$.

${ }^{54}$ STJUE 22 septiembre 2011, Interflora/Marks \& Spencer, C-323/09, ECLI:EU:C:2011:604, apartado 62.

55 Vid. F. CARBAJo CASCón, "Problemas de distribución, marcas y responsabilidad indirecta de intermediarios en plataformas de agregación de comercio electrónico. Comentario a la STJUE 12 julio de 2012 (Caso L'oreal c. eBay) y jurisprudencia relacionada", $R c d, \mathrm{n}^{\mathrm{o}} 10,2012$, p. 174.

${ }^{56}$ DO L 178, de 17 de julio de 2000. Sobre esta Directiva sin carácter exhaustivo vid. en la doctrina extranjera, E. CRABIT, "La Directive sur le commerce électronique. Le Project 'Méditerranée", RDUE, No 4, 2000, pp. 449-831; L. EDwARDs, "The problem of Intermediary Service Provider Liability", en L. Edwards, The new legal framework for E-Commerce in Europe, Hart Publishing, Oxford-Portland, Oregon, 2005, pp. 93-136;A. L. LODDER, "Directive 2000/31/EC on certain legal aspects of information society services in particular electronic commerce, in the internal market", en A. LODDER /A.D. MURRAY (Eds.), EU-Regulation of E-Commerce. A Commentary, Edward Elgar, 2017, pp.; en la doctrina española, A. LóPeZ-TARruella, "A European Community Regulatory Framework for Electronic Commerce”, $C M L R$, vol. 38, n6, 2011, pp. 1337-1384; R. YANGUAS Gómez, Contratos de conexión a Internet, Hosting y búsqueda, Civitas, Madrid, 2012. 
El objetivo de esta Directiva era eliminar los obstáculos que existían entre los Estados miembros en materia de comercio electrónico. Uno de ellos era la diferente normativa nacional en materia de responsabilidad de los prestadores de servicio que actúan como intermediarios en internet. Este aspecto se unificó mediante los arts. 12 a 14 DCE, y regula la exención de responsabilidad ante determinadas actividades (puertos seguros o safe harbours ${ }^{57}$ ) para los prestadores de servicios on line que operan como intermediarios. Sin embargo, la DCE no armoniza los sistemas de responsabilidad de los Estados miembros ${ }^{58}$. Así, el Derecho nacional sigue jugando un papel importante a la hora de acabar determinando la responsabilidad última de la plataforma. En el caso de una conducta no pueda quedar exenta porque no cae dentro de "los puertos seguros" de la DCE no significa que inmediatamente a esa actuación de la plataforma se le pueda imputar responsabilidad ${ }^{59}$. Será necesario acudir a la normativa concreta de los Estados miembros y si se cumple lo que se señala el Derecho interno al respecto. En el Derecho español, en defecto de normativa específica habrá que atender al régimen general de responsabilidad civil extracontractual (art. 1902 CC). Un aspecto importante es que la DCE abarca todo tipo de infracciones, no sólo las que nos interesan en el presente estudio (las civiles), también las penales y las administrativas ${ }^{60}$.

46. A pesar de que la DCE continua en vigor, no hay que olvidar que sus deficiencias son evidentes en relación a algunos de modelos de negocio y servicios digitales actuales. Esto es así porque su origen tuvo lugar hace más de 20 años cuando muchos de los servicios que se prestan hoy en internet ni tan si quiera existían en aquella época ${ }^{61}$. A pesar de ello, el legislador europeo ha optado por no derogarla y tendrá que convivir con la Directiva 2019/790 de 17 de abril de 2019 sobre los derechos de autor y derechos afines en el mercado único digital y por la que se modifican las Directivas 96/9/CE y 2001/29/ $C E^{62}$, la cual intenta afrontar algunos de los problemas que ocasionan algunos de los ilícitos que en la actualidad se producen en la red y que afectan a la propiedad intelectual. Aún así, los días de la DCE están contados, la Comisión Europea está preparando un nuevo marco legal en relación a los servicios digitales al que ha denominado Digital Services Act Package. En la actualidad esta nueva regulación se encuentra en fase de consulta pública hasta el próximo 8 de septiembre de 2020.

\section{Los servicios exentos de responsabilidad}

\section{A) Introducción}

47. La DCE en su sección 4 recoge las actividades por las cuales los prestadores de servicios en internet estarían exentos de responsabilidad. Estos servicios serían: 1) el servicio de transmisión y

\footnotetext{
${ }^{57}$ Sobre el origen de la expresión "safe harbour" vid. J. Riordan, The Liability of Internet Intermediaries, Oxford University Press, Oxford, 2016, p. 378. Este autor hace referencia a que "safe harbour" proviene de un aforismo marítimo donde un buque maltrecho busca un puerto seguro en una fuerte tormenta, el buque está en el puerto seguro pero no es ese el lugar que le corresponde. Aplicado a la responsabilidad de las plataformas se pueden extraer las siguientes conclusiones: 1) Los prestadores de servicios en internet están expuestos a fuerzas impredecibles que no pueden controlar. Sería como una tormenta en medio del mar para un buque; 2) Ante esa situación los prestadores necesitan seguridad para poder operar, es decir, un puerto en el que refugiarse hasta que la tormenta pase; 3 ) Ese puerto seguro no lo es al 100\%, la responsabilidad de la plataforma puede resurgir en mitad de un mar calmado. Cómo maneje la plataforma esa situación será clave para su propia supervivencia.

${ }^{58}$ E. Arroyo Amayuelas, "La responsabilidad de los intermediarios en internet: ¿puertos seguros a prueba de futuro?, CDT, "Vol. $12, \mathrm{n}^{\mathrm{o}} 1$, p. 809.

${ }^{59}$ Ibidem, p. 809.

${ }^{60}$ J. Riondan, The Liability of..., p. 384. En la jurisprudencia vid. STJUE de 11 de septiembre de 2014, Sotiris Papasavvas/ Fileleftheros Dimosia, C-291/13, ECLI:EU:C:2014:2209, apartado 50. Para un mayor detalle sobre ilícitos penales que pueden dar lugar a que a la plataforma se le reclame responsabilidad civil vid. J.P. CoRTÉs LABADÍA, "Responsabilidad civil de los prestadores de servicios de la sociedad de la información derivada de delitos de injurias y calumnias con publicidad", Diario La Ley, ${ }^{\circ}$ 9674, 15 julio 2020.

${ }^{61}$ Un ejemplo de ello podrían ser las redes sociales como Instagram o WhatsApp y también las plataformas que permiten ver series, películas o documentales en streaming como Netflix o Amazon prime video.

${ }^{62}$ DOUE 130/92, de 17 de mayo de 2019.
} 
acceso a los datos (art. 12 DCE); 2) los servicios de caching (art. 13) ; 3) los servicios de alojamiento de datos o hosting (art. 14 DCE).

\section{B) El servicio de transmisión y acceso a los datos (art. 12 DCE)}

48. El art. 12 de la DCE se refiere a dos servicios: la transmisión de datos y el acceso a los mismos. Aunque son dos actividades diferentes, en el plano de la responsabilidad no hay diferencia alguna ${ }^{63}$. Este tipo de servicios permite que el usuario se pueda conectar a la red, bien por cable o de forma inalámbrica. El servicio del proveedor es puramente técnico, mediante el cual se le asigna una IP, y no tendrá responsabilidad por la transmisión de lo datos o facilitar acceso a los mismos siempre que los datos hayan sido facilitados por el destinatario del servicio, y además:

a) no haya originado el mismo la transmisión;

b) no seleccione al destinatario de la transmisión; y

c) no seleccione ni modifique los datos transmitidos.

En relación a este último aspecto que el prestador del servicio "no modifique los datos transmitidos", el considerando 43 señala que no se considera modificación de datos "las manipulaciones técnicas" que tienen lugar en el curso de la transmisión. Así, actuaciones de la plataforma que se podrían englobar dentro del art. 12 y beneficiarse de la exención de responsabilidad podrían ser las siguientes ${ }^{64}$ : a) la comprensión de datos para reducir el tamaño de un fichero;b) la eliminación automática de los virus o spam de los emails; c) la fragmentanción de los archivos.

\section{C) EI servicio de caching (art. 13 DCE)}

49. Respecto de los servicios de caching o de memoria tampón consisten en los servicios que permiten el almacenamiento temporal, automático y provisional de información. Este es un servicio muy técnico conocido como cache web que permite que internet no se sature y los usuarios puedan navegar por internet más rápidamente. Los proveedores de estos servicios están exentos de responsabilidad en atención al art. 13 DCE. Este precepto no merece mayor detenimiento debido a que no ha generado problemas jurídicos a destacar salvo aquellos en relación a empresas que han intentado englobar su servicio dentro del precepto y no lo han conseguido ${ }^{65}$.

\section{D) El servicio de hosting (art. 14 DCE)}

50. Uno de los preceptos más importantes de la DCE, o al menos uno de los que más desarrollo judicial ha tenido, es su art. 14. Este precepto se refiere al servicio de hosting o de alojamiento de datos. La importancia de este precepto es debido a que una gran parte de los servicios digitales que ofrecen las plataformas no sólo de ecommerce también las que permiten alojar vídeos, las de e-learning o las relativas a redes sociales quedaría englobado dentro de servicio de hosting. Esto es posible debido a que la DCE define el servicio de hosting en términos muy generales, así señala el "almacenamiento de datos facilitados por el destinatario del servicio".

${ }^{63}$ M. Peguera Poch, "Los prestadores de servicios de internet y la normative sobre responsabilidad", en A. LóPez TARrueLLA, DERECHO TIC, Derecho de las tecnologías de la información y de la comunicación, Valencia, Tirant lo Blanch, 2016 , p. 9.

${ }^{64}$ E. Arroyo Amayuelas, "La responsabilidad de..., p. 820. Vid también UK Department of Trade and Industry, A guide for business to the Electronic Commerece (EC Directive) Regulations 2002, p. 25, disponible en https://webarchive.nationalarchives.gov.uk/20130103013730/http://www.bis.gov.uk/files/file14635.pdf(consultado el 12 de junio de 2020).

${ }^{65} \mathrm{Vid}$. M. Peguera Poch, "Los prestadores de...",p. 10. 
De este modo, un aspecto clave será precisar quién es destinatario. Así, el destinatario del servicio es aquél que proporciona los datos para que la plataforma los almacene. Es decir, el que quiere publicar contenidos en un blog, el que quiere publicar un vídeo en youtube o un comentario en twitter. Pero también el que ofrece un producto designado con una marca en una plataforma de ecommerce. Como ya hemos estudiado, en materia de infracción de marca, será clave determinar quién (si la prestador -la plataforma- o el destinatario del servicio -el vendedor-) usa la marca. Ésta se usa por aquél que persigue ofrecer o comercializar los productos, en definitiva por el que hace una comunicación comercial del signo.

51. El aspecto clave que permite que la plataforma no sea responsable por el servicio de almacenamiento es el conocimiento efectivo de que ese almacenamiento genera un ilícito y también cómo actúa ante ese conocimiento. Así, el art. 14 señala que una plataforma no será responsable de los datos almacenados a petición del destinatario cuando:

1) el prestador del servicio no tenga conocimiento efectivo de que la actividad de información es ilícita.

2) el prestador del servicio actúa rápidamente bien retirando la información o impidiendo el acceso a la misma en cuanto tiene conocimiento de la ilicitud de la actividad.

La doctrina ha precisado que cuando se trata de dirimir la responsabilidad de la plataforma en relación a una acción por daños y perjuicios se exige un conocimiento más riguroso que en relación a la responsabilidad penal ${ }^{66}$. Así, el art. 14 DCE señala que en el caso de responsabilidad civil derivada de daños y perjuicios es necesario que la plataforma no hubiera tenido un "conocimiento efectivo de hechos o circunstancias por las que la actividad o la información revele su carácter ilícito".

52. En relación a la retirada o bloqueo de la información, el prestador del servicio debe en todo caso respetar la libertad de expresión y siempre teniendo en cuenta los procedimientos que a tal fin existan a nivel nacional ${ }^{67}$.

53. Por último, hay que tener presente que la exención de responsabilidad no resultaría de aplicación cuando el destinatario del servicio actúe bajo la autoridad o control del prestador del servicio (art. 14.2 DCE). Con este precepto se persigue que el prestador sea realmente un intermediario. Este escenario puede tener lugar cuando el destinatario del servicio trabaje para el prestador del servicio, esa neutralidad de la plataforma desaparece, deja de ser un mero intermediario debido a esa función de supervisión que ejerce sobre el destinatario del servicio ${ }^{68}$. Hay doctrina que ha precisado que lo importante es el control que se ejerce sobre el destinatario no tanto sobre la información en sí ${ }^{69}$. Sin embargo, esto no puede predicarse así en todo caso. La plataforma podría ejercer control en el sentido del art. 14.2 DCE en los siguientes supuestos relacionados con el control de información ${ }^{70}$ :

1) La información o contenido se genera por el destinatario pero bajo los términos y condiciones que fija el prestador del servicio. Es decir, el intermediario detalla qué se puede publicar o que no o incluso se reserva la posibilidad de editar contenidos. Esto podría suceder en plataformas como Facebook o Wikipedia.

2) El prestador del servicio puede ejercer de moderador de un chat o un grupo.

\footnotetext{
${ }^{66}$ M. Peguera Poch, "Los prestadores de servicios...", p. 11.

${ }^{67}$ Considerando 46 DCE.

${ }^{68}$ Sobre este particular vid. M. Barrios Andrés, Fundamentos del Derecho de internet, Centro de Estudios Políticos y Constitucionales, Madrid, 2017, p. 381. Vid también, E. Arroyo Amayuelas, "La responsabilidad de..., p. 821.

${ }^{69}$ A. L. LODDER, "Directive 2000/31/EC on..., p. 52.

${ }^{70}$ E. Arroyo Amayuelas, "La responsabilidad de..., p. 821; M. Barrios Andrés, Fundamentos del Derecho..., p. 84. En contra vid. apartado 1.3.3 de la Recomendation CM/Rec (2018) the Committee of Ministers to member States on the roles and responsibilities of internet intermediaries, disponible en https://search.coe.int/cm/Pages/result_details.aspx?ObjectID=0900001680790e14 (consultado el 12 de junio de 2020).
} 


\section{El rol de la plataforma en la jurisprudencia del TJUE: ¿ posición neutral o agente activo?}

54. La responsabilidad por la infracción de derechos de marca por parte de las plataformas de comercio electrónico va a estar ligada a qué actividad desempeñan. Como se ha analizado, la Directiva 2000/31/CE sobre comercio electrónico, en su artículo 14, señala que los prestadores de servicios de Hosting o almacenamiento de datos no serán responsables de los datos que almacenan cuando no tengan conocimiento efectivo del carácter ilícito de los mismos o cuando teniendo dicho conocimiento actúen con prontitud para retirarlos o para que sean inaccesibles (excepción de responsabilidad de puerto seguro). En el mismo sentido se pronuncia artículo 16 de la Ley 34/2002, de 11 de julio, de servicios de la sociedad de la información y de comercio electrónico ${ }^{71}$ (en adelante LSSICE).

De este modo, cuando la actividad de la plataforma de comercio electrónico o motor de búsqueda sea la de alojar datos, actuar como simple intermediario no tendrá responsabilidad respecto a las infracciones del derecho de marca que los clientes realicen desde las plataformas ${ }^{72}$. En otras palabras, los productos de marca podrán ser vendidos mediante sus plataformas sin que se les pueda pedir responsabilidad aunque dichas ventas impliquen infracción de un Derecho de marca.

55. Actualmente el problema radica, como ya se ha analizado, en que las plataformas en muchas ocasiones no actúan en el tráfico jurídico como meros intermediarios ${ }^{73}$. Es decir, intervienen de forma activa en los procesos de comercialización de sus clientes, teniendo conocimiento de que los productos comercializados por sus clientes infringen derechos de propiedad industrial e intelectual ${ }^{74}$. El Tribunal de Justicia ha considerado que no toda actividad de almacenamiento de datos va a estar exenta de responsabilidad en virtud del art. 14 DCE. Dicha exención no es posible cuando el prestador del servicio "en lugar de limitarse a una prestación neutra de dicho servicio mediante un tratamiento meramente técnico y automático de los datos facilitados por sus clientes, desempeña un papel activo que le permite adquirir conocimiento o control de tales datos ${ }^{\prime \prime 75}$. Este papel activo puede reflejarse en conductas como optimizar la presentación de ofertas de venta o promover activamente las ofertas que le permitan tener un conocimiento efectivo de los datos relativos a las mismas ${ }^{76}$.

56. Por lo tanto, es posible llegar a la conclusión de que aunque el TJUE mantiene en los casos que se le han planteado que la responsabilidad del prestador del servicio quede exenta es necesario que tenga una posición neutral y meramente técnica. Esto explica las diferentes soluciones alcanzados en el asunto Google/L.Vuitton y en el asunto $L^{\prime}$ Oreal/ eBay. En el primer caso, el TJUE consideró que Google tenía una posición neutral, mientras que en el segundo caso, consideró que eBay no tenía tal posición, sino que ocupaba una posición activa. En el reciente asunto del TJUE en el que se enfrentan ante tribunales alemanes Coty Germany/Amazon, el Tribunal de Justicia no se pronunció sobre la responsabilidad de la plataforma Amazon $^{77}$. Sin embargo, sí que lo hizo el Abogado General CAmpos SÁnCHEZ-Bordona.

\footnotetext{
71 BOE núm. 166, de 12 de julio de 2002.

${ }^{72} \mathrm{Vid}$. M. SchriJvers, "European Court Rules on the Position of eBay Regarding the Sale of Infringing Products: L'Oreal v eBay", EIPR, vol. 33, n 11, 2011, pp. 724.

${ }^{73} \mathrm{Vid}$. M. Peguera Poch, "Infracción de derechos de marca en las plataformas de subasta en línea y la aplicación de las normas de exclusión de responsabilidad", IDP Revista de Internet, Derecho y Política, núm. 8, 2009, disponible en hhttp//: idp. uoc.edu.(consultado el 9 de junio de 2020).

${ }^{74}$ Vid. F. Carbajo Cascón, "La marca en los sistemas de distribución selectiva (el problema de las ventas paralelas)", en E. Galán Corona/F. Carbajo Cascón (Coord.), Marcas y distribución comercial, Ediciones Universidad de Salamanca, 2011, p. 208.

${ }^{75}$ STJUE 12 julio 2011, L'Oreal y otros/ eBay Internatial AG y otros, C-324/09, ECLI:EU:C:2011:474, apartado 113. Esta interpretación fue controvertida, ya que el TJUE aplicó el considerando 42 de la DCE al art. 14 DCE, cuando en realidad a dicho artículo le correspondía el considerando 46. Sobre las críticas de la doctrina al respecto vid., M. Peguera Poch, "Los prestadores de servicios...", pp. 16-17; J.LÓPEZ RICHARD, "Un nuevo regimen de responsabilidad para las plataformas de almacenamiento de contenidos generados por usuarios en el mercado único digital", RPI, $\mathrm{n}^{\circ}$ 60, 2018, pp. 83-84.J. Riordan, The Liability of ..., p. 402.

${ }^{76}$ STJUE 12 julio 2011, L Oreal y otros/ eBay Internatial A G y otros, C-324/09, ECLI:EU:C:2011:474, apartado 116.

${ }^{77}$ STJUE 2 abril 2020, Coty/Amazon, C-567/18, ECLI:EU:C:2020:267, apartados 50-51.
} 
En dichas Conclusiones, el Abogado General destaca que en el caso de que el tribunal nacional confirme que Amazon realiza todas las actividades que en su propia web afirma que lleva a cabo dentro de su programa de "Amazon Logística", su actuación no es neutra. Es decir, el almacén de las mercancías, su empaquetado, el envío del producto y la atención al cliente son actividades que no permiten que Amazon pueda considerarse un mero intermediario. Amazon no sólo se encarga de la creación de las condiciones técnicas para que su cliente venda productos a través de su plataforma, su actuación va más allá ${ }^{78}$. Por lo tanto, Amazon no podría beneficiarse de la exención de responsabilidad del art. 14.1 DCE, se consideraría que está usando la marca sobre la que Coty Gemany ostenta la titularidad, y por lo tanto, se le podría solicitar que cesara en la infracción de la misma y responsabilidad marcaria por su actuación. Sin embargo, no deja de ser el tribunal nacional (en este caso el Tribunal Supremo alemán) el que acabará decidiendo y valorando si en atención a las circunstancias concretas la exención de responsabilidad se le podría aplicar a Amazon $^{79}$. En definitiva, los tribunales nacionales son los que han ido adaptando la regulación europea existente a las necesidades que surgen por las actuaciones que se realizan en internet por las plataformas ${ }^{80}$.

57. En conclusión, la jurisprudencia del TJUE ha utilizado los términos "activos" y "pasivos" para determinar cuando la plataforma actúa como mero intermediario. La plataforma no puede refugiarse en el puerto seguro del art. 14.1 DCE si desempeña un rol activo. Para determinar ese rol es necesario ir más allá del contenido literal de los términos "activos" y "pasivos" jurisprudencia del TJUE, el juzgador para valorar la neutralidad de la plataforma debe tener en cuenta: 1) el grado de participación que la plataforma ejerce sobre el negocio del destinatario del servicio; 2)la intervención específica de la plataforma en la generación de contenido ${ }^{82}$.

Sin embargo, a pesar de que una interpretación más allá del tenor literal es adecuada, no elimina la imprecisión por completo. Los nuevos roles que desempeñan las plataformas debido al avance en los servicios digitales en los últimos veinte años hace que esos términos (activo y pasivo) en realidad sean muy estrechos. En aras de paliar esta situación hay doctrina que ha señalado que sería interesante

78 Conclusiones Abogado General M. Campos Sánchez sobre el asunto presentados el 28 de noviembre de 2019, ECLI:EU:C:2019:1031, apartados 58 y 62.

${ }^{79}$ Esto tiene un riesgo y es que provocaría que cada Estado miembro aplique la exclusión de responsabilidad de forma diferente. Y de hecho así sucede. La sentencia de la Cour d'appel de Reims de 20 de julio de 2010, Hermès International/eBay, Chambre Civile, 1. ${ }^{a}$ section, sigue la doctrina del TJUE establecida en el caso Google. En esta resolución francesa se considera que eBay no es simple alojador de datos debido a que su actividad va más allá de un servicio meramente técnico, automático y pasivo. Esta plataforma tiene conocimiento sobre los datos que sus clientes almacenan. Es más, el Tribunal considera que usa la notoriedad de la marca para llamar la atención de los usuarios para que acudan al sitio web de sus clientes donde se venden productos falsificados. Del mismo modo, en términos parecidos se pronuncia la Cour d`appel el 3 de septiembre de 2010 en tres asuntos que tenían de nuevo como protagonista a eBay, eBay/Louis Vuitton Malletier, eBay/Parfums Christian Dior et autres y eBay/Christian Dior Couture, en estas resoluciones el tribunal francés siguiendo la doctrina Google considera que eBay no puede acojerse a la exención de responsabilidad prevista para los prestadores de servicios de alojamiento de datos al desempeñar una actividad que dista mucho de ser neutral, ya que eBay, se dedicaba a la asistencia y promoción de las ventas de productos de comerciantes paralelos. Sin embargo, no llega a la misma conclusión el Tribunal de Commerce de Bruxelles en una sentencia de 31 de julio de 2008, Parfums et Beauté \& CieleBay International AG, eBay Europe s.a.r.l., et s.p.r.l. eBay Belgium, en la que considera que es necesario analizar las actividades de eBay por separado para saber si se pueden beneficiar de la exclusión de responsabilidad. Así, las actividades de mero alojamiento de datos podrían beneficiarse de la exclusión mientras que el resto deberían regirse por las normas generales de responsabilidad. Para un mayor estudio de estas resoluciones vid. M. PEGUERA Poch, "Infracción de derechos de marca en las plataformas de subasta en línea y la aplicación de las normas de exclusión de responsabilidad", IDP Revista de Internet, Derecho y Política, núm. 8, 2009, disponible en hhttp//: idp.uoc.edu. (consultado el 13 de junio de 2020).

${ }^{80}$ En la jurisprudencia española vid. ad ex. SAP de Madrid de 19 de enero de 2018, nº 53/2018, ECLI:ES:APM:2018:1978 en la que se considera que la actuación de Google es lícita desde el punto de vista marcario (FJ 38) pero también desde el punto de vista de la competencia desleal (FJ 60). Para la AP la actuación de Google es meramente técnica, ya que se limita a procesar, organizar y presentar la información y no se ocupa de redactar el texto del anuncio que acompaña al enlace promocional. También en la misma línea, la SAP de Alicante de 10 de octubre de 2017, n 391/2017, ECLI:ES:APA:2017:2676, FJ 6 en la que se considera que el impresor de unos folletos, cuya impresión se encarga por un tercero, se debe considerar un intermediario, y que su actuación no constituye un uso de marca ajena.

${ }^{81}$ M. Peguera Poch, "Los prestadores de servicios...", p. 17.

${ }^{82}$ Ibidem, p. 93. 
dejar atrás esos términos para dar paso a otros más precisos como "grado de control de la plataforma" o "conocimiento efectivo" 83 . Desde nuestro punto de vista, esa propuesta es acertada. El rol "activo" o "pasivo" ya no es suficiente para precisar la responsabilidad de las plataformas en unos mercados digitales donde los servicios digitales son cada vez más dinámicos y complejos.

\section{El deber de diligencia de la plataforma}

58. La exención de responsabilidad del art. 14 DCE no resulta de aplicación cuando a pesar de que la plataforma ocupa una posición neutral, tiene "conocimiento efectivo" de que la actividad o los datos que almacenan sus clientes son ilícitos y no hace nada para retirarlos o hacer su acceso imposible ${ }^{84}$.

El término "conocimiento efectivo" se interpreta por el TJUE de forma menos restrictiva que la recogida en la $\mathrm{LSSICE}^{85}$. El TJUE en la sentencia $L$ 'Oreal considera que para considerar que existe conocimiento efectivo es necesario que el prestador del servicio haya tenido conocimiento de hechos o circunstancias a partir de los cuales un operador económico diligente hubiera debido deducir ese carácter ilícito y haber actuado en consecuencia ${ }^{86}$

Sin embargo, este deber de diligencia no se puede traducir en un deber de vigilancia permanente $^{87}$. Como analizaremos posteriormente, el art. 15.1 DCE no permite un control general sobre el contenido que alberga la plataforma. Esto supondría una carga excesiva, tanto en coste económico como en esfuerzo para la plataforma. De este modo, ante la falta de una especificación clara de ese deber de diligencia tanto por parte de la DCE como del TJUE será en el caso concreto donde se deberá valorar si la plataforma ha actuado adecuadamente.

59. A nuestro juicio el deber de diligencia de la plataforma debe variar considerablemente en atención al rol de la plataforma en la comercialización de los productos. Si la plataforma de ecommerce es un mero almacenista, no se le puede exigir que conozca al detalle todos y cada uno de los productos que ofertan sus vendedores, su deber de diligencia se debe limitar al tipo de función que desarrolla, que en este caso es auxiliar.

En contraposición, ese deber de diligencia debe cambiar considerablemente cuando la plataforma de ecommerce no es un mero intermediario, su actuación no es neutral y participa activamente en la oferta y comercialización de los productos que sus vendedores le hacen llegar. Este sería el caso del reciente asunto Coty/Amazon que hemos comentado anteriormente ${ }^{88}$. Cuando un vendedor de Amazon se suscribe a su programa de logística, esta plataforma desarrolla claramente un papel activo. No sólo se encarga del almacenamiento de las mercancías, también de su empaquetado, de su envío y del servicio postventa. No criticamos el rol de la plataforma, es un negocio, pero sí que se debe revisar su diligencia. Si desarrolla un papel activo en la venta, estaría usando la marca de un tercero, y por lo tanto, para evitar infracciones debería cerciorarse de que esos productos son respetuosos con los derechos de marca. A nuestro juicio, esa exigencia no es excesiva cuando la plataforma actúa como vendedor no como plataforma que sólo aporta condiciones técnicas para que sus clientes-vendedores vendan productos mediante su plataforma.

Por lo tanto, el deber de diligencia debe adaptarse a la tecnología y al modelo concreto de empresa $^{89}$. Este deber debería incluso modularse en atención al rol que puede llegar a desempeñar la pla-

\footnotetext{
83 E. Arroyo Amayuelas, "La responsabilidad de...", p. 817.

${ }^{84}$ STJUE 12 julio 2011, L'Oreal y otros/ eBay Internatial AG y otros, C-324/09, ECLI:EU:C:2011:474, apartado 119.

${ }^{85}$ En los arts. 16 y 17 de la LSSICE se recoge que el prestador de servicios tiene el conocimiento efectivo cuando "un órgano competente haya declarado la ilicitud de los datos, ordenado su retirada o que se imposibilite el acceso a los mismos, o se hubiera declarado la existencia de la lesión, y el prestador conociera la correspondiente resolución, sin perjuicio de los procedimientos de detección y retirada de contenidos que los prestadores apliquen en virtud de acuerdos voluntarios y de otros medios de conocimiento efectivo que pudieran establecerse".

${ }^{86}$ STJUE 12 julio 2011, L Oreal y otros/ eBay Internatial AG y otros, C-324/09, ECLI:EU:C:2011:474, apartado 120.

${ }^{87}$ E. Arroyo Amayuelas, "La responsabilidad de...", p. 823.

${ }^{88}$ STJUE 2 abril 2020, Coty/Amazon, C-567/18, ECLI:EU:C:2020:267.

${ }^{89}$ E. Arroyo Amayuelas, "La responsabilidad de...", p. 823.
} 
taforma en ese caso concreto. Sin embargo, no al contrario. Es decir, pueden existir dudas para algunas plataformas de si ejercer o no un mayor diligencia con el fin de evitar la prevención de ilícitos contra la propiedad industrial para evitar que las autoridades consideren que su rol va más allá del de un mero intermediario. La Comisión Europea ha advertido que una mayor diligencia por parte de la plataforma no pueden implicar de forma automática un comportamiento activo en el sentido del art. 14 DCE $^{90}$. Es decir, esas medidas adoptadas de forma voluntaria para prevenir o detectar ilícitos no pueden ir en detrimento de la plataforma considerando que por adoptarlas su comportamiento es activo.

\section{La vía para que la plataforma identifique los hechos ilícitos: la notificación}

60. La DCE no establece cómo ni tampoco quién debe notificar la infracción que se está llevando a cabo en una plataforma ${ }^{91}$. De este modo, sería necesario diferenciar entre los casos en los que existe resolución judicial o administrativa estableciendo que existe un ilícito marcario de los que no existe.

En el caso de existir una resolución al respecto, la notificación a la plataforma la realizaía la autoridad pertinente. Sin embargo, en el supuesto de que no contar con una resolución judicial o administrativa, la notificación de la infracción de una marca en una determinada plataforma la llevaría a cabo el propio titular de esos derechos. También incluso podría notificarlo un tercero a la plataforma, el cual podría ser un particular o también una entidad.

61. En relación a los mecanismos para presentar notificaciones, las plataformas deben facilitar la notificación. A ésta se debería poder acceder fácilmente y con la posibilidad de que pudiera llevarla a cabo cualquiera de los usuarios de la plataforma ${ }^{92}$. Un aspecto interesante a plantearse es si ante cualquier notificación se podría considerar que la plataforma tiene ese "conocimiento efectivo" que señala el art. 14 DCE. La realidad es que no debería ser así. No toda notificación por el mero hecho de tener lugar puede significar que la plataforma tiene conocimiento de un ilícito cometido en su plataforma. La notificación debe ser suficientemente precisa y estar debidamente fundamentada en aras de poder permitir a la plataforma tomar una determinación al respecto ${ }^{93}$. No obstante, los hechos del caso concreto serán especialmente relevantes para determinar si se puede entender que una notificación ha dado lugar a que la plataforma tuviera un conocimiento efectivo y que implique responsabilidad por su parte en atención al art. 14 DCE en el caso de no haber actuado al respecto.

Sobre este particular se puede apreciar como la práctica de las autoridades de los diferentes países europeos es distinta ${ }^{94}$. En España ha habido tribunales que han considerado que la notificación del inicio de acciones civiles a la plataforma no era suficiente. Así, se ha exigido una resolución judicial para considerar que la información a la que remitía el buscador no era veraz ${ }^{95}$.

En Alemania se exige que la notificación se redacte de forma precisa y detallada con el fin de que la plataforma pueda identificar fácilmente la normativa aplicable ${ }^{96}$. La obligación de la plataforma de examinar la notificación de que en su sitio web se está cometiendo un ilícito depende mucho del tipo de ilícito en si mismo.

\footnotetext{
${ }^{90}$ Comunicación de la Comisión de 2 de junio de 2016 al Parlamento Europeo, al Consejo, al Comité económico y social europeo y al Comité de las Regiones. Una Agenda Europea para la economía colaborativa, Bruselas, COM(2016), 256 final, p. 8.

${ }_{91}$ Sobre este particular vid. la Recomendación (UE) 2018/334 de la Comisión de 1 de marzo de 2018 sobre medidas para combatir eficazmente los contenidos ilícitos en línea (DOUE L 63/50, de 6 de marzo de 2018).

${ }_{92}$ Recomendación (UE) 2018/334 de la Comisión de 1 de marzo de 2018 sobre medidas para combatir eficazmente los contenidos ilícitos en línea, considerando 16.

${ }^{93}$ Ibidem, considerando 17.

94 Vid. E. Arroyo Amayuelas, "La responsabilidad de...", p. 823.

${ }^{95}$ STS de 4 de marzo de 2013, n $^{\circ}$ 144/2013, ECLI:ES:TS:2013:2245.

${ }^{96}$ E. Arroyo Amayuelas, "La responsabilidad de...", p. 824.

BGHD de 17 de Agosto de 2011, ZR 57/09, StiftparfÜm.Disponible en http://www.olnhausen.com/rechtsprechung/urteile-2011/bgh-urteil-v-17-8-2011-i-zr-5709-stiftparfum/

(consultado el 14 de junio de 2020).
} 
En Francia, es necesario que se identifique al notificante, se describan los hechos, se prueben los mismos y se argumente el porqué de la ilicitud del contenido en relación a la normativa de aplicación al caso ${ }^{97}$.

\section{Medidas que se podrían exigir a la plataforma}

62. Un aspecto clave es qué medidas judiciales se pueden emprender contra las plataformas cuando en las mismas se infringen derechos de marca con independencia de la responsabilidad que acabe teniendo la plataforma en el asunto concreto. De este modo, cabría preguntarse si sería posible exigirles que actúen para que acaben con las lesiones del derecho de marca, bloqueado las cuentas de los usuarios, o que instauren medidas en el futuro que eviten dichas violaciones en sus sitios webs. Uno de los aspectos que nos planteamos es si una solución podría ser la exigencia a la plataforma de que monitorice los contenidos de su plataforma. Es decir, que se pudiera obligar a la plataforma a supervisar en términos generales sus contenidos. En definitiva, a buscar actos ilícitos cometidos a través de su plataforma en general.

La respuesta es tajante: esto no es posible. Hay un aspecto importante que no se puede pasar por alto y es que el art. 15 DCE no exige un deber general de supervisión a la plataforma ${ }^{98}$. Así, una Ley de un Estado miembro ni tampoco una resolución judicial podría obligar a una plataforma de ecommerce o a cualquier tipo de prestador de servicio por internet a que monitorice contenidos ${ }^{99}$. Ad ex. no se podría obligar a la plataforma a implantar un sistema de filtrado mediante el cual se le obliga a un supervisión activa de todos los datos de sus clientes para evitar infracciones en materia de derechos de autor ${ }^{100}$.

63. La clave es que exista un equilibrio, entre el desarrollo de un negocio, que es lo que persigue la plataforma y el respeto a los Derechos de propiedad industrial e intelectual. Esto implica dos bazas importantes para las plataformas a tener en cuenta para defender su actuación, estas serían:

1) La plataforma no puede ser obligada a supervisar de forma generalizada sus contenidos para identificar a las personas o las informaciones que infringen los derechos de un tercero. Esa obligación de identificación recaería en el titular de tales derechos ${ }^{101}$.

2) El perjudicado no puede realizar una identificación general de que alguien infringe sus derechos. El titular debe precisar quién infringe esos derechos. Es decir, el perjudicado debe señalar en la plataforma $\mathrm{X}$, el vendedor $\mathrm{Y}$ comercializa productos que lesionan la marca $\mathrm{Z}$, sobre la cual ostenta su titularidad.

Por lo tanto, el hecho de que no se pueda obligar a la plataforma a una supervisión general sobre los contenidos no obsta para que los Estados miembros exijan colaboración a las mismas que permita identificar a los destinatarios de sus servicios (art. 15.2 DCE). En definitiva, este precepto habilitaría a los Estados a que las plataformas pudieran espiar a sus usuarios para detectar la comisión de ilícitos ${ }^{102}$. Especialmente esta exigencia podría tener sentido cuando se trata de perseguir graves ilícitos que tienen que ver con actividades como el terrorismo o la pornografía infantil.

No obstante, a la hora de decidir qué obligaciones se pueden exigir a la plataforma será necesario valorar equilibradamente los derechos en juego ${ }^{103}$. Esa ponderación debe tener en cuenta no sólo los intereses de los titulares de los Derechos vulnerados sino también de los usuarios de internet y de la

\footnotetext{
${ }^{97}$ Cour de cassation, chamber civile 1, de 17 de febrero de 2011, 09-67896, Dailymotion. Disponible en https://www.legifrance.gouv.fr/affichJuriJudi.do?idTexte=JURITEXT000023607266 (consultado el 14 de junio de 2020).

${ }^{98}$ Así lo manifestó el TJUE en el asunto L'Oreal y otros/ eBay, apartado 139.

${ }_{99}$ M. Peguera Poch, "Los prestadores de servicios...", p. 13.

${ }^{100}$ STJUE 14 de noviembre de 2011, Sabam/Starlet, C-70/10, ECLI:EU:C:2011:77, apartados 40, 47 y 48.

${ }^{101}$ M. Peguera Poch, "Los prestadores de servicios...", p. 13.

${ }^{102}$ E. Arroyo Amayuelas, "La responsabilidad de..., p. 827. Vid. también.

${ }^{103}$ STJUE 27 marzo 2014, Telekabel, C-314/12, ECLI:EU:C:2014:192, apartado 46.
} 
plataforma ${ }^{104}$. De este modo, se deberían evitar medidas extremas como cerrar por completo la conexión a internet ${ }^{105}$. Si medidas menos coercitivas son posibles, son las que se deberían exigir a la plataforma, ya que casarían mejor con el principio de libertad de empresa.

Por lo tanto, la imposición legal o judicial a las plataformas de una obligación generalizada de supervisión no es posible en atención al art. 15.1 DCE. Lo que sí se puede es exigir medidas concretas contra un mismo infractor para evitar que el ilícito se siga cometiendo. El TJUE no se centra tanto en las medidas concretas sino que se deberían dictar medidas que conjuguen los siguientes valores ${ }^{106}: 1$ ) adaptación los recursos y capacidades de la plataforma; 2) compatibilidad con el resto de obligaciones a los que la plataforma debe hacer frente en el ejercicio de su actividad; 3) previsibilidad para la plataforma. Son medidas que se podían esperar de la plataforma para impedir el resultado prohibido.

En el asunto $L$ 'Oreal/eBay una de las medidas que se destaca es requerir a eBay que identifique a los infractores de DPII que operan en su plataforma. El infractor como opera en el tráfico económico debe ser claramente inidentificable en atención al art. 6 DCE, ya que ésta exige que deben ser susceptibles de identificación todas aquellas personas físicas o jurídicas que realicen ofertas comerciales mediante internet ${ }^{107}$. Por este motivo, eBay al proporcionar los datos de los operadores de su plataforma no estaría cometiendo ningún ilícito relacionado con la protección de datos personales.

64. En el Derecho nacional de marcas, el art. 41.3 LM se establece que, con independencia de la responsabilidad de los intermediarios, los tribunales les pueden exigir tanto medidas para que las lesiones al derecho de marca finalicen como medidas para evitar futuras lesiones del mismo tipo ${ }^{108}$. El mismo artículo de la LM recoge que el carácter de las medidas debe ser objetivo, proporcionado y no discriminatorio ${ }^{109}$.

En definitiva, la posibilidad de que dichas medidas se lleven a cabo hace que el comportamiento del operador del comercio electrónico sea más riguroso. Sabe que su actuación en cierta medida se monitoriza, especialmente por los titulares de los derechos de propiedad industrial e intelectual. De este modo, el operador es consciente de que si en su plataforma se lesionan derechos, ostente o no responsabilidad, debe acatar las medidas que los tribunales puedan llegar a imponerles para evitar que la lesión continúe. A nuestro juicio, lo ideal para la plataforma sería intentar evitar llegar a esa fase de imposición de medidas. Sería interesante apostar por la autorregulación ${ }^{110}$ y que mediante la implantación de políticas internas permitieran implementar actuaciones ex ante que permitan ser más rigurosos con los derechos de terceros ${ }^{111}$.

\section{Conclusiones}

65. El objeto del presente trabajo ha sido doble. Por un lado, el estudio de los supuestos en los que se puede considerar que una marca está siendo usada por una plataforma de ecommerce. Por el otro,

${ }^{104}$ Ibidem, apartado 56.

105 STJUE 15 septiembre 2016, Tobbias MacFadden, C-484/14, ECLI:EU:C:2016:689, apartados 88 y 89.

106 STJUE 27 marzo 2014, Telekabel, C-314/12, ECLI:EU:C:2014:192, apartados 52-54.

107 Ibidem, apartado 142.

${ }^{108}$ No hay que olvidar que las acciones que pueden ejercitarse frente a la plataforma que actúa como mero intermediario son independientes y autónomas con respecto a las acciones que se pueden ejercitar frente al infractor de la marca. Si la plataforma es un mero intermediario las acciones que se le pueden solicitar en virtud del art. 43.1 LM se limitan únicamente 1) a la cesión de los actos si hubiera infracción por parte de quien utiliza la plataforma y 2) a la remoción de los efectos a los que se refiere el art. 41.1 c) LM. En ningún se le va a condenar por infringir la marca. Vid. sobre este particular la SAP de Alicante de 10 de octubre de 2017, nº 391/2017, ECLI:ES:APA:2017:2676, FJ 6.

${ }^{109}$ En definitiva se persigue ese justo equilibrio entre derechos en juego, en la línea de lo sontenido por el TJUE en sentencias como la de 24 de noviembre de 2011, Scarlet extended, C-70/10, EU:C:2011:771, apartado 49 o la de julio de 2015, Coty Germany/Stadtsparkasse Magdeburg, C-580/13, apartado 35.

${ }^{110}$ Sobre este particular vid. E. Arroyo Amayuelas, "La responsabilidad de..., pp. 830-833.

${ }^{111}$ Comunicación de la Comisión de 20 de septiembre de 2017 al Parlamento Europeo, al Consejo, Al Comité Económico y social Europeo y al Comité de las regions, Lucha contra el contenido ilícito en línea. Hacia una responsabilización de las plataformas en línea, Bruselas, COM (2017) 555 final, pp. 11-13. 
el análisis de cuándo la plataforma podría ser responsable de los ilícitos que contra la propiedad industrial se cometen desde su sitio web. Como se ha estudiado, las actuaciones que se pueden llevar a cabo desde internet en relación a la oferta y comercialización de productos pueden ser muy variadas entre sí. Desde la oferta y comercialización de productos cuyos derechos de marca no se han agotado, productos sin embalaje, la venta de muestras o la venta de keywords por buscadores que coinciden con marcas. El aspecto importante para saber si la plataforma usa una marca es atender a la comunicación personal. Si la marca de un tercero es usada por una plataforma para su propia comunicación personal, para ofrecer o vender productos se entenderá que existe uso de una marca en el sentido del R. 2017/1001.

66. Sin embargo, que la plataforma no use la marca en el sentido del citado Reglamento no significa que esté exento de toda responsabilidad por las infracciones de propiedad industrial que se pueden cometer en su sitio web. Así, hemos estudiado como en el caso concreto es necesario atender a la actuación de la plataforma en atención a la DCE. Si su actuación es neutral, la de mero intermediario, se podría acoge a la exención de responsabilidad que se recoge en el art. 14 DCE. Sin embargo, si su posición es activa, podría perder ese puerto seguro y ser considerado responsable de las infracciones que se cometen en su plataforma. La clave será saber que rol desempeña la plataforma en el negocio de su cliente, el que le pide que aloje datos (que oferte productos en la plataforma). Con las mismas consecuencias, puede darse la situación de que la plataforma es neutral, pero no ha actuado cuando tenía conocimiento de que en su plataforma se estaban infringiendo derechos marcarios. En ese caso, tampoco podría acogerse al puerto seguro del citado art. 14. Para evitar este segundo escenario, el deber de diligencia de la plataforma es crucial. Sin embargo, este deber de diligencia no puede confundirse con un deber de vigilancia generalizada. No sabemos en un futuro, pero a día de hoy, ese debe de vigilancia permanente no puede ser exigido a las plataformas en virtud del art. 15.1 DCE.

67. Por lo tanto, aunque el caso particular será clave para analizar cuál es el papel de la plataforma y cómo ha actuado, a nuestro juicio, el análisis jurídico que plantean estos asuntos es realmente complejo. Esto es así no sólo por la determinación de si en el caso concreto es de aplicación el art. 14 DCE sino porque el Derecho de los Estados miembros tiene mucho que decir en estos asuntos. En el caso de que la actuación de la plataforma no se le aplique la exención de responsabilidad se deberá atender a las normas del Derecho nacional que resulte de aplicación. Uno de los aspectos a determinar conforme al Derecho nacional es si la plataforma aunque no use la marca en el sentido de la normativa marcaria, pero aún así su actuación no quede exenta de responsabilidad, qué infracción estaría cometiendo.

En un primer momento se podría pensar en una infracción indirecta de la marca ${ }^{112}$. Esto es, el prestador del servicio, está ayudando o facilitando a que otros, los clientes de la plataforma o los anunciantes cuando se trata de motores de búsqueda, lesionen el derecho de marca de un tercero. Sin embargo, en las legislaciones de los Estados miembros, y en concreto en la española, no existe este tipo de infracción indirecta sobre la marca ${ }^{113}$. De este modo, cabe preguntarse qué opciones legales le quedan al titular de la marca si por infracción de la misma el camino está cerrado. Ante este panorama, la reclamación de daños y perjuicios vía responsabilidad extracontractual sería un opción a tener en cuenta, junto con las acciones vía competencia desleal por promover en el mercado las actividades desleales de un tercero ${ }^{114}$.

\footnotetext{
112 Vid. F. CARBajo CAscón, "La marca en...", p. 210.

113 Esta infracción indirecta de la marca se podría asemejar al contributory infrigment del Common Law. Esta figura es importante en aras de proteger los derechos de propiedad intelectual e industrial debido a que el titular puede no sólo perseguir al infractor propiamente dicho sino también a quien le facilita dicha infracción.

${ }^{114}$ F. CARBAJo CASCón, "La marca en...", p. 211.
} 